\title{
Development of Ruthenium Complex Based Sensitizers, Organic Based Sensitizers, and Co- sensitization System for Dye-sensitized Solar Cells
}

\author{
K.F. Chan', H.N. Lim ',2,", N.M. Huang ${ }^{3}$, H. Ahmad' \\ ${ }^{1}$ Department of Chemistry, Faculty of Science, Universiti Putra Malaysia, 43400 UPM Serdang, Selangor, Malaysia \\ ${ }^{2}$ Materials Synthesis and Characterization Laboratory, Institute of Advanced Technology, Universiti Putra Malaysia, \\ 43400 UPM, Serdang, Selangor, Malaysia \\ ${ }^{3}$ School of Energy and Chemical Engineering, Xiamen University Malaysia, Selangor Darul Ehsan 43900, Malaysia \& College of \\ Chemistry and Chemical Engineering, Xiamen University, Xiamen 361005, China \\ *Corresponding authors: E-mail: hongngee@upm.edu.my \\ DOI: 10.5185/amlett.2020.061522
}

This paper reviews the recent development of ruthenium complex sensitizers, organic sensitizers, and co-sensitizers for dye-sensitized solar cell (DSSC) applications. The development of ruthenium sensitizers has progressed from thiocyanate (NCS) ligands containing bipyridyl, terpyridyl, quarterpyridyl, and cyclometalated ruthenium sensitizers to NCS-free analogs. The integration of organic moieties and ruthenium complex ancillary ligands into a single structure entity was also achieved in the DSSC industry. The development of organic sensitizers as an alternative to ruthenium-based sensitizers was also discussed according to their functional segment: donor, acceptor, and $\pi$-spacer. The modification of donor groups has been focused on introducing ancillary groups to increase the molar extinction coefficient and electron recombination resistance. Anchoring groups other than cyanoacrylic acids have been developed to improve the anchoring ability of organic sensitizers while maintaining their light-harvesting properties. A study was performed on $\pi$-spacers modified with different conjugation lengths and conjugated side chains in order to enhance the charge transfer within organic sensitizers. Co-sensitization systems, including metal-metal, metal-organic, and organic-organic systems with stepwise and "cocktail" co-sensitization methods will be discussed in this review.

\section{Introduction}

Dye-sensitized solar cells (DSSCs) are regarded as the third generation of solar cells because a breakthrough was made in 1991 by Gratzel and co-workers as a candidate for high conversion low-cost photovoltaic devices through the combination of nanostructured electrodes and photosensitive sensitizers [1]. These photovoltaic cells employ nanotechnology and molecular scale interfaces to enable electron transfer driven by photoexcitation and an appropriate electronic energy pathway. In DSSCs, the kinetics of the charge separation is subject to the electrochemical reaction involved. The utilization of mesoporous titanium dioxide $\left(\mathrm{TiO}_{2}\right)$ as a semiconductor improved the efficiency of DSSCs from 1\% (non-porous surface) to $7 \%$. By having sensitizer molecules chemically adsorbed on the semiconductor surface, the light photons are absorbed by the molecules instead of the semiconductor itself, where the charge transport process takes place [2]. Nanosized electrode semiconductors have given rise to prolonged charge carrier lifespans, an enhanced redox potential for electron-hole pairs, and the replacement of solid-state electron mediators by liquid state electrolytes [3]. Hence, DSSCs have become the subjects of multi-disciplinary research involving solidstate photovoltaic and classical regenerative photo- electrochemical cells featuring nanoscale construction to establish a novel photoconversion system.

A DSSC is composed of two electrodes made up of two indium tin oxide (ITO) or fluorine-doped tin oxide (FTO) glasses (photoanode and a counter electrode) sandwiching an electron mediator, as shown in Fig. 1a. The operating cycle of a DSSC is shown in Fig. 1b. Upon the illumination of sunlight on the device, photons are absorbed by sensitizer molecules in the photoanode, causing the sensitizer to be oxidized. Electrons are injected into the $\mathrm{TiO}_{2}$ conduction band and the external circuit, which generates a photocurrent, while the oxidized sensitizer will be regenerated by the redox electrolyte, which will be regenerated at the counter electrode.

The sensitizer is a key component used to define the light harvesting capability and the electron transfer system of the device [4]. An ideal sensitizer should meet the following criteria: 1) it must be photosensitive to the light spectrum below $900 \mathrm{~nm}$; 2) it contains anchoring groups such as carboxylate or phosphonate moieties to enable the formation of a chemical linkage with the $\mathrm{TiO}_{2}$ surface; 3) it should have a high redox potential to enable the rapid regeneration of oxidized sensitizer species; and 4) the lowest unoccupied molecular orbital (LUMO) energy level should be a good match to that of the lower bound of the conduction band to ensure efficient electron injection [5]. 


\section{Advanced Materials Letters www. vbripress.com/aml}

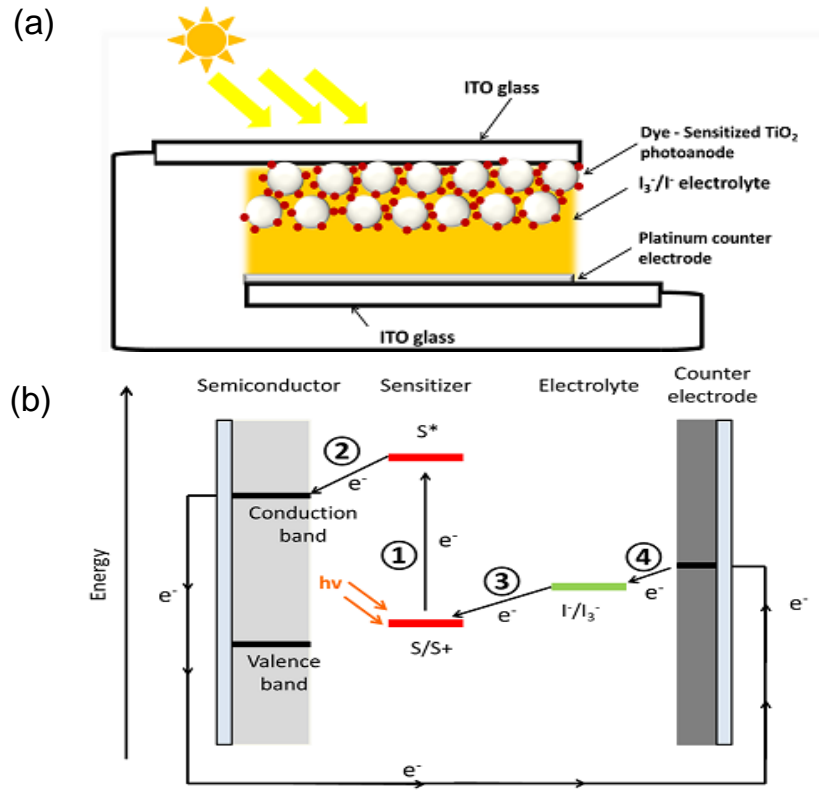

Fig. 1. (a) Schematic diagram of DSSC device and fundamental components. (b) Energy level diagram of a DSSC. (1) Photoexcitation of electrons. (2) Electron injection. (3) Regeneration of oxidized sensitizer. 4) Regeneration of oxidized electrolyte.

N719 and black dye are the paradigms of efficient ruthenium sensitizers established by Grätzel and coworkers $[\mathbf{1 , 6}]$. Since then, various ruthenium sensitizers have been synthesized to enhance light harvesting properties and photoconversion efficiency. In particular, ruthenium polypyridyl complexes have been the bestperforming sensitizers, as indicated by N719 (power conversion efficiency of $12 \%$ with $\mathrm{J}_{\mathrm{SC}}=12 \mathrm{mAcm}^{-2}$ ) [1] and black dye (power conversion efficiency of $10.4 \%$ with $20.5 \mathrm{mAcm}^{-2}, \mathrm{~V}_{\mathrm{OC}}=0.72 \mathrm{~V}, \mathrm{FF}=0.7$ ) [7]. However, organic chromophores have been gaining attention because of their low material cost and high molar absorption coefficient and ease of structural modification [8]. Co-sensitization emerged as the solution to the light absorption limitation of a single sensitizer by enabling the sensitization of two complementary sensitizers on a semiconductor surface. The timelines for the development of ruthenium sensitizers, organic sensitizers, and cosensitizers are illustrated in Fig. 2. The study of ruthenium bipyridyl sensitizers started in the early 1990s and was followed by the study of terpyridyl, quarterpyridyl, and metal-free cyclometalated ruthenium sensitizers. Innovation on bipyridyl sensitizers such as amphiphilic and ion-coordinating ruthenium sensitizers has been done. The development of organic sensitizers started in the early 2000s when alternative sensitizers were developed to overcome the drawbacks of ruthenium sensitizers. Various types of organic compounds have been developed as an effort to improve the efficiency of DSSCs. On the other hand, the idea of a co-sensitization system was introduced in the late 2000s when an organic-organic co-sensitization system was developed. Since then, the study has been extended to metal-organic and metal-metal cosensitization systems with stepwise and "cocktail" mixed dye approaches. In this paper, we will review recent developments in the molecular engineering of ruthenium sensitizers, organic chromophores, and the study of the cosensitization systems. There are on-going efforts to achieve a wider absorption range for sensitizers, which includes the visible light, ultra-violet (UV), and infrared red (IR) ranges and thus higher efficiencies.

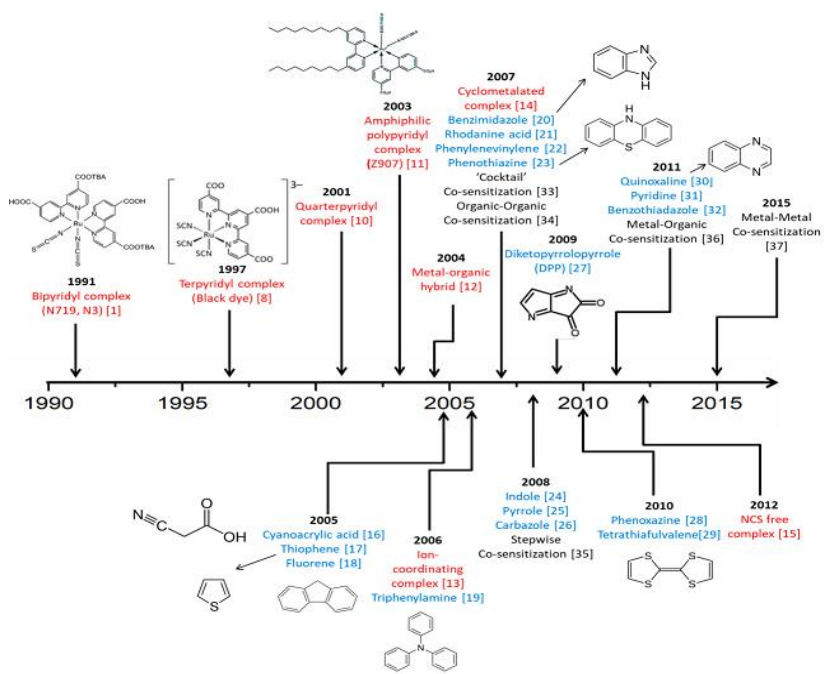

Fig. 2. Development timeline of ruthenium sensitizers, organic sensitizers, and co-sensitization system.

\section{Ruthenium sensitizers}

Polypyridyl ruthenium complexes have been strong candidates for DSSC sensitizers because of their intensive light harvesting capacity over the visible light range, highly stable excited and reduced state [9], and electronic energy level that is compatible with the conduction band of a metal oxide semiconductor [10]. The discussions of ruthenium sensitizers in this review include polypyridyl complex sensitizers (bipyridyl, terpyridyl, and quarterpyridyl), NCS-free ruthenium sensitizers, and metal-organic hybrid sensitizers. The absorption maxima and photovoltaic efficiencies of ruthenium complex sensitizers are summarized in Table 1. The molecular structures of sensitizers from dye 1 to dye 14 are displayed in Fig. 3, while those from dye 15 to dye 32 are displayed in Fig. 4.

\section{Polypyridyl complex sensitizers}

Recently, modifications of the bipyridine ligand by thiophene-based $\pi$-conjugated light harvesting moieties have been reported. Thienylvinyl $\pi$-conjugated bipyridyl ligand with an incorporated ruthenium sensitizer (dye 1) generates a low open circuit voltage $\left(\mathrm{V}_{\mathrm{OC}}\right)$ as a result of its shorter electron lifetime, which encourages the charge recombination process at the $\mathrm{TiO}_{2} /$ sensitizer/electrolyte interface, despite the generation of a high short circuit current density $\left(\mathrm{J}_{\mathrm{SC}}\right)$ through the $\pi$-conjugation system [11]. The generation of a lower $\mathrm{V}_{\mathrm{OC}}$ was also observed for a ruthenium bipyridyl complex modified with bulk hydrocarbon (1,1-dipropyl butyl and 1,1-dimethyl hexyl) on thiophene groups, as shown by dye 2 and dye 3 , mainly 


\section{Advanced Materials Letters www. vbripress.com/aml}

caused by inefficient dye packing, which subjected the $\mathrm{TiO}_{2}$ surface to electron recombination [12]. Nonetheless, a solution was found for the ineffective dye packing due to the thiophene-based bulky ligand when a new ruthenium sensitizer incorporating a dissymmetric 5-hexylthiophene with substituted bipyridine ligand (dye 4) was found to improve the interfacial properties through three carboxylic anchoring groups, rendering the same $\mathrm{V}_{\mathrm{OC}}$ to that of N719 under a similar condition [13].

Table 1. Reviewed ruthenium complex sensitizers and their respective maximum absorption values, molar extinction coefficients, and PCEs.

\begin{tabular}{|c|c|c|c|c|c|c|}
\hline $\begin{array}{l}\text { Sensitiz } \\
\text { ers }\end{array}$ & $\begin{array}{c}\text { Maximum absorption }\left(\lambda_{\max }\right) \\
/ \mathbf{n m} \\
{[\text { Molar extinction coefficient }} \\
\left.(\varepsilon) / \mathbf{M}^{-1} \mathbf{c m}^{-1}\right]\end{array}$ & $\begin{array}{c}\mathbf{J s c}_{\mathrm{sc}} \\
\underset{\mathbf{m A c}}{\left.\mathbf{m}^{-2}\right)}\end{array}$ & $\begin{array}{l}\mathbf{V}_{\text {oC }} \\
\text { (V) }\end{array}$ & FF & 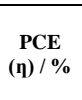 & Ref. \\
\hline \multicolumn{7}{|c|}{ i) Bipyridyl } \\
\hline \multicolumn{7}{|c|}{$\begin{array}{cc}\text { Thiophene-based } \\
\end{array}$} \\
\hline dye 1 & $350(35167), 542(16100)$ & 16.8 & 0.6 & 0.5 & 5.2 & [11] \\
\hline dye 2 & 522 & 14.9 & 0.7 & 0.7 & 7.0 & \multirow{2}{*}{ [12] } \\
\hline dye 3 & 532 & 15.7 & 0.7 & 0.7 & 7.6 & \\
\hline dye 4 & $524(18000)$ & 15.3 & 0.7 & 0.7 & 7.6 & {$[13]$} \\
\hline \multicolumn{7}{|c|}{ Long chain hydrocarbon } \\
\hline dye 5 & \begin{tabular}{l|l|}
$299(4480), 370(1200), 518$ \\
$(1080)$
\end{tabular} & 7.0 & 0.7 & 0.7 & 3.3 & [14] \\
\hline \multicolumn{7}{|c|}{ Ion-coordinating } \\
\hline dye 6 & $\begin{array}{l}310(28500), 486(10600), \\
530(9700)\end{array}$ & 4.0 & 0.5 & 0.7 & 1.3 & [15] \\
\hline dye 7 & $541(11883), 393(14250)$ & 14.9 & 0.7 & 0.7 & 6.9 & [16] \\
\hline \multicolumn{7}{|c|}{ ii) Terpyridyl } \\
\hline dye 8 & $523\left(\begin{array}{lll}10 & 023\end{array}\right)$ & 10.4 & 0.7 & 0.8 & 5.4 & \multirow{2}{*}{ [17] } \\
\hline dye 9 & $441(25418)$ & 10.0 & 0.6 & 0.8 & 4.9 & \\
\hline dye 10 & $\begin{array}{l}280(30000), 331(23600), \\
422(14700), 606(7000)\end{array}$ & 18.0 & 0.6 & 0.7 & 7.6 & [18] \\
\hline dye 11 & 450,630 & 22.7 & 0.7 & 0.7 & 10.7 & \multirow{2}{*}{ [19] } \\
\hline dye 12 & 450,630 & 22.4 & 0.7 & 0.7 & 10.3 & \\
\hline dye 13 & 402 (42700), $532(26270)$ & 14.2 & 0.6 & 0.7 & 6.2 & [20] \\
\hline \multicolumn{7}{|c|}{ iii) Quarterpyridyl } \\
\hline dye 14 & $\begin{array}{l}298(32000), 400(35500), \\
615(7500)\end{array}$ & 19.2 & 0.4 & 0.7 & 5.7 & [21] \\
\hline \multicolumn{7}{|c|}{ iv) Cyclometalated } \\
\hline dye 15 & $543(2400), 426(2500)$ & 15.4 & 0.7 & 0.7 & 7.0 & [22] \\
\hline dye 16 & $384(880), 537(600)$ & 13.4 & 0.8 & 0.7 & 7.2 & [23] \\
\hline dye 17 & $\begin{array}{l}335(3800), 393(12900), \\
520(13500)\end{array}$ & 18.9 & 0.5 & 0.6 & 6.4 & [24] \\
\hline dye 18 & $578(23900)$ & 13.9 & 0.8 & 0.7 & 8.2 & [25] \\
\hline \multicolumn{7}{|c|}{ v) NCS-free } \\
\hline \multicolumn{7}{|c|}{$\begin{array}{l}\text { Pyridyl-azolate ligand } \\
\end{array}$} \\
\hline dye 19 & $\begin{array}{l}309(33000), 341(32000), \\
433(15000), 501(22000)\end{array}$ & 18.7 & 0.8 & 0.7 & 10.2 & \multirow{2}{*}{ [26] } \\
\hline dye 20 & $\begin{array}{l}308(27000), 318(26000, \mathrm{sh}) \\
417(10000), 473(17000)\end{array}$ & 15.4 & 0.7 & 0.7 & 8.3 & \\
\hline dye 21 & $\begin{array}{l}385(12400), 444(9100), \\
497(11200)\end{array}$ & 8.2 & 0.6 & 0.7 & 3.4 & [27] \\
\hline dye 22 & $\begin{array}{l}379(11500), 482(11000), \\
575(2500)\end{array}$ & 15.2 & 0.5 & 0.7 & 4.9 & [28] \\
\hline \multicolumn{7}{|c|}{$\begin{array}{c}\text { Bipyridyl dipyrrinate } \\
\text {. }\end{array}$} \\
\hline dye 23 & $560(18300)$ & 13.8 & 0.4 & 0.6 & 3.4 & [29] \\
\hline \multicolumn{7}{|c|}{ Pyridine } \\
\hline dye 24 & \begin{tabular}{l|}
$418(9500), 498(7600), 563$ \\
$(8200)$
\end{tabular} & 18.0 & 0.7 & 0.5 & 5.3 & [30] \\
\hline \multicolumn{7}{|c|}{ vi) Metal-organic hybrid } \\
\hline \multicolumn{7}{|c|}{ Triphenylamine-based } \\
\hline dye 25 & \begin{tabular}{l|}
$310(41100), 343(28400)$, \\
$446(34200), 553(5900)$
\end{tabular} & 4.5 & 0.6 & 0.7 & 2.0 & [31] \\
\hline dye 26 & $524(30861)$ & 18.3 & 0.7 & 0.7 & 9.0 & [32] \\
\hline dye 27 & $419(23500), 519(16600)$ & 11.8 & 0.7 & 0.7 & 5.8 & [33] \\
\hline dye 28 & $\begin{array}{l}331(41000), 437(37500), \\
574,527(29600), 681 \\
(2900)\end{array}$ & 16.7 & 0.7 & 0.7 & 8.0 & [34] \\
\hline dye 29 & $\begin{array}{l}310(56200), 399(41700), \\
538(18400)\end{array}$ & 18.5 & 0.7 & 0.7 & 10.1 & \multirow{2}{*}{ [35] } \\
\hline dye 30 & \begin{tabular}{l|l}
$307(60100), 392(56400)$, \\
$554(24300)$
\end{tabular} & 18.9 & 0.7 & 0.7 & 10.1 & \\
\hline \multicolumn{7}{|c|}{ Phenothiazine and Diphenylamino-based } \\
\hline dye 31 & \begin{tabular}{l|}
$298(35900), 342(30200)$, \\
$520(10500)$
\end{tabular} & 17.1 & 0.7 & 0.7 & 9.1 & [36] \\
\hline dye 32 & $\begin{array}{l}268(11200), 291(12600), \\
342(3120), 518(1030)\end{array}$ & 5.5 & 0.6 & 0.6 & 2.1 & [37] \\
\hline
\end{tabular}

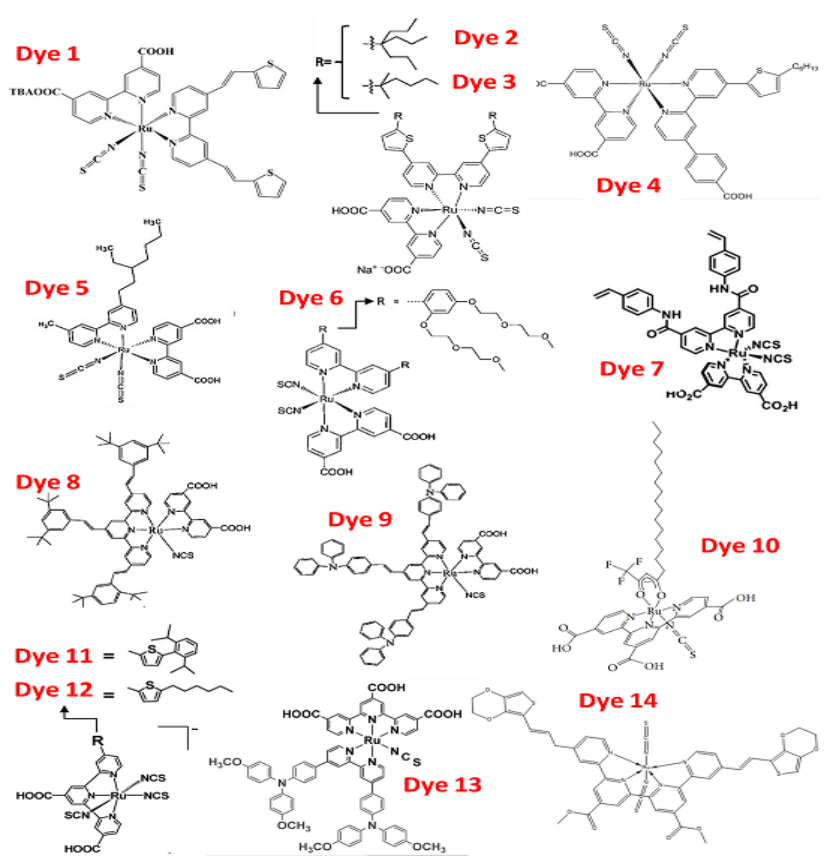

Fig. 3. Molecular structures of dye 1, reproduced with permission from Ref. [11] (Copyright (2011) The Royal Society of Chemistry); dye 2 and dye 3, reproduced with permission from Ref. [12] (Copyright (2012) The Royal Society of Chemistry); dye 4, reproduced with permission from Ref. [13] (Copyright (2014) The Royal Society of Chemistry); dye 5, reproduced with permission from Ref. [14] (Copyright (2015) Elsevier); dye 6, reproduced with permission from Ref. [15] (Copyright (2016) Wiley); dye 7, reproduced with permission from Ref. [16] (Copyright (2013) The Royal Society of Chemistry); dye 8 and dye 9, reproduced with permission from Ref. [17] (Copyright (2011) The Royal Society of Chemistry); dye 10, reproduced with permission from Ref.[18] (Copyright (2011) Hindawi); dye 11 and dye 12, reproduced with permission from Ref.[19] (Copyright(2015) American Chemical Society); dye 13, reproduced with permission from Ref. [20] (Copyright (2011) The Royal Society of Chemistry); dye 14, reproduced with permission from Ref.[21] (Copyright (2011) The Royal Society of Chemistry).

The effect of dissymmetry was also applied to the branched alkyl bipyridine ligands of ruthenium complexes (dye 5) when a study found that different branched groups did not impose an important effect on the spectroscopic and electrochemical properties. However, a sensitizer with highly conjugated dissymmetric alkyl bipyridyl ruthenium complexes gives rise to higher efficiency compared to those with low conjugated or symmetric ligands [14].

Ion-chelating bipyridyl ruthenium sensitizers have wettability in an aqueous electrolyte, which is more environmentally friendly and safer than iodine-based organic electrolytes. Ruthenium sensitizers with various lengths of ethylene glycol (dye 6) were synthesized for a $100 \%$ aqueous electrolyte DSSC and outperformed N719 under the same conditions [15]. Ethylene glycol functions to maintain the wettability of the $\mathrm{TiO}_{2}$ photoanode and sensitizer, whereby the longest ethylene glycol chain exhibits the highest efficiency $(\eta=1.34 \%)$. Another bis(strylaminocarbonyl)-substituted ruthenium sensitizer (dye 7) was capable of chelating triiodide anion, which could reduce the charge recombination by keeping the triiodide ions away from contact with the mesoporous $\mathrm{TiO}_{2}$ layer [16]. The electron-withdrawing amide group in the ligand also contributed to a higher molar extinction coefficient, which in turn increased the photocurrent for the DSSC. 


\section{Advanced Materials Letters www. vbripress.com/aml}

Terpyridyl ruthenium sensitizers with $2,2^{\prime} ; 6,2^{\prime \prime}$ terpyridine have been modified with $\pi$-conjugated substituents such as 3,5-di-tert-butyl phenyl (dye 8) or triphenylamine (dye 9) [17], $\beta$-diketone ligands with a long alkyl chain (dye 10) [18], and an n-hexylthiophene (dye 11) or 2,6-diisopropylphenylthiophene unit (dye 12) [19]. This modification gives a higher molar extinction coefficient than unmodified ruthenium sensitizers despite a lower dye loading amount. More recently, a study on the replacement of labile NCS in terpyridyl ruthenium complexes by efficient electron-donating ancillary ligands enabled excellent optical and chemical characteristics, which was shown using a DSSC sensitized by dye 13 [20]. The resulting device also exhibited excellent stability at $60{ }^{\circ} \mathrm{C}$ for $1000 \mathrm{~h}$. For a quarterpyridyl sensitizer, a heteroarylvinylene $\pi$-conjugated quaterpyridyl ruthenium sensitizer (dye 14) applied in DSSCs gave high absorption over the visible light spectrum and reached a $33 \%$ incident photo-to-current conversion efficiency (IPCE) at the near infra-red region. This was attributed to the introduction of the EDOT-vinylene conjugated substituent, which increases the highest unoccupied molecular orbital (HOMO) energy level and lowered the LUMO energy level, rendering a lower energy gap [21].

\section{Cyclometalated ruthenium sensitizers}

Cyclometalated ruthenium complexes are known for their unique electron localization and stability. In a recent study, the substitution of different moieties to cyclometalated ruthenium complexes was attempted. These included naphthalimide units (dye 15) [22] and difluorobenzyl groups (dye 16) [23]. The electron withdrawing property of the 1,8-naphthalimide fragment allows a more thermodynamically favorable electron regeneration process. The removal of the alkoxy group and replacement of the octyl chain with a 3,5-difluorobenzyl substituent on the carbine-pyridine group showed a $13 \%$ increase in efficiency. The synthesis and study of the absorption of cyclometalated ruthenium complexes with 6-(orthomethoxyphenyl)-2,2'-bipyridine (dye 17) on $\mathrm{TiO}_{2}$ was done [24]. It was shown that the deprotonated carboxylate form of ruthenium complexes reached an efficiency of $6.4 \%$, and the presence of a cation was effective in retarding the recombination reaction. A study has also been done on the effects of different donor substituents on tris-heteroleptic cyclometalated ruthenium complexes. The different effects of the $N$-Hexylcarbazole, $N$-hexylphenothiazine, and $N$-hexyldiphenylamine donor moieties are generally due to different electron lifetimes, where the complexes bearing the $N$-hexylphenothiazine donor (dye 18) exhibited a higher electron lifetime and efficiency $(\eta=8.2 \%)[25]$.

\section{NCS-free ruthenium sensitizers}

NCS-free ruthenium sensitizers have been extensively studied because of the fragility of the NCS ligand, which leads to the stability of the sensitizer complex. The main strategy is to replace the NCS ligand with the pyrazolate ligand and its derivatives, including triazolate and tetrazole groups. A study of pyrazolate (dye 19) and triazolate-containing sensitizers (dye 20) showed that the photovoltaic performance of triazole-containing sensitizers is inferior to that with pyrazolate because of the increased optical band gap induced by the electron withdrawing feature of the triazolate chelate [26]. On the other hand, pyridyl-tetrazolate ligands were also used to replace NCS in a ruthenium sensitizer (dye 21), but lower light harvesting properties and $\mathrm{J}_{\mathrm{SC}}$ values were observed [27]. Another NCS-free bis(tridentate) ruthenium sensitizer with the bis(tetrazolyl)pyridine ligand as the ancillary ligand (dye 22) yielded an efficiency of $6.10 \%$ [28], indicating the feasibility of using the pyridine-azole based ligand to replace the NCS groups in the ruthenium sensitizer.

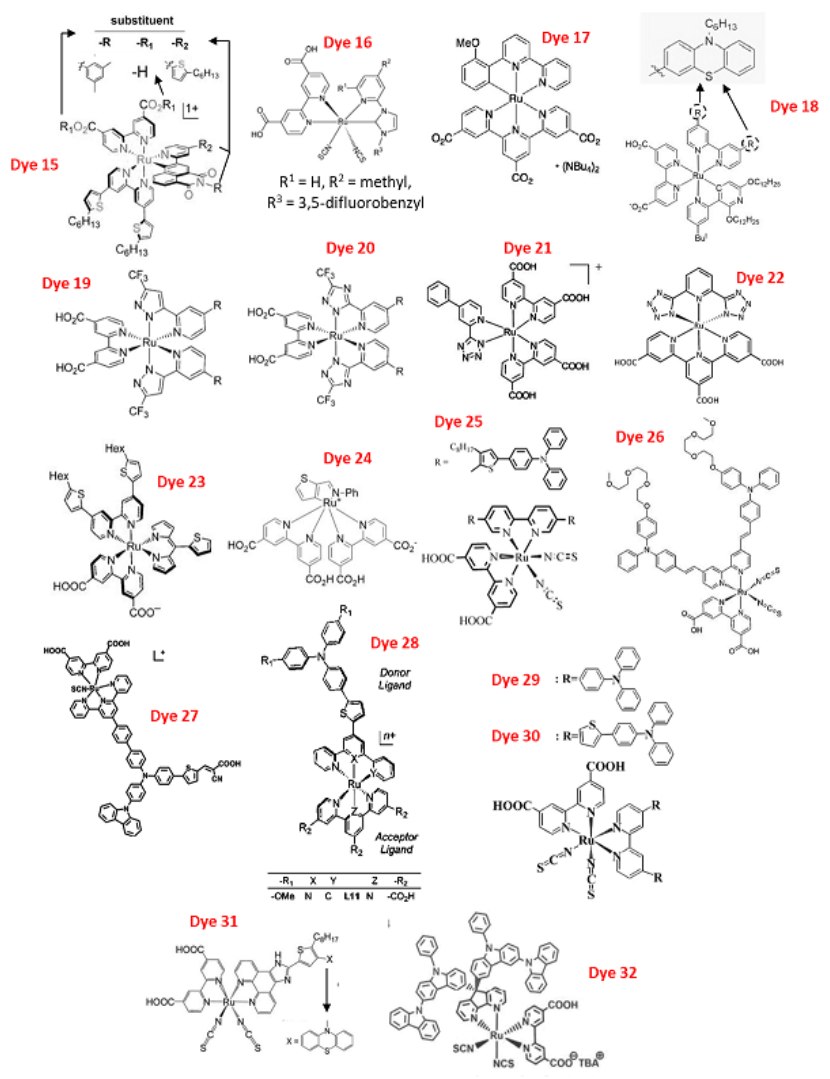

Fig. 4. Molecular structures of dye 15, reproduced with permission from Ref. [22] (Copyright (2013) The Royal Society of Chemistry); dye 16, reproduced with permission from Ref. [23] (Copyright (2011) The Royal Society of Chemistry); dye 17 reproduced with permission from Ref. [24] (Copyright (2017) Elsevier); dye 18, reproduced with permission from Ref. [25] (Copyright (2017) American Chemical Society); dye 19 and dye 20, reproduced with permission from Ref. [26] (Copyright (2013) The Royal Society of Chemistry); dye 21, reproduced with permission from Ref. [27] (Copyright (2015) The Royal Society of Chemistry); dye 22, reproduced with permission from Ref. [28] (Copyright (2015) Elsevier); dye 23, reproduced with permission from Ref. [29] (Copyright (2014) Wiley); dye 24, reproduced with permission from Ref. [30] (Copyright (2017) Elsevier); dye 25, reproduced with permission from Ref. [31] (Copyright (2011) The Royal Society of Chemistry); dye 26, reproduced with permission from Ref. [32] (Copyright (2011) Elsevier); dye 27, reproduced with permission from Ref. [33] (Copyright (2015) The Royal Society of Chemistry); dye 28, reproduced with permission from Ref. [34] (Copyright (2011) American Chemical Society); dye 29 and dye 30, reproduced with permission from Ref. [35] (Copyright (2014) The Royal Society of Chemistry); dye 31, reproduced with permission from Ref. [36] (Copyright (2012) The Royal Society of Chemistry); dye 32, reproduced with permission from Ref. [37] (Copyright (2017) The Royal Society of Chemistry). 


\section{Advanced Materials Letters www. vbripress.com/aml}

An NCS-free tris-heteroleptic ruthenium complex sensitizer incorporating dipyrrins and hexylthiophene substituted bipyridines (dye 23) has been studied [29]. The corresponding DSSC exhibited an efficiency of $3.4 \%$, which was attributed to the more negative excited state redox potentials and efficient electron injection into the $\mathrm{TiO}_{2}$ conduction band. On the other hand, a cycloruthenated thiophene-based ruthenium sensitizer with orthosubstituted pyridine on metallated thiophene has been developed and exhibited a higher efficiency of 5.3\% (dye 24) compared to other known cycloruthenated thiophenes, as a result of its broad metal-to-ligand charge transfer (MLCT) bands and high extinction coefficients [30].

\section{Metal-organic hybrid sensitizers}

Hybrid sensitizers that combine a metal complex and organic chromophores into one structural entity have emerged as a new category of DSSC sensitizers. The combination of the ruthenium complex and triphenylamine organic moiety has been widely studied in a hybrid system. The combination of triphenylamine and thiophene moieties at 5,5'-positions (dye 25) shows great potential compared to typical 4,4'-transitions because of its more accessible synthesis [31]. Triphenylamine groups with various substituents in hybrid sensitizers have been studied. Ethylene glycol incorporated as a donor ligand on the triphenylamine ligand for a ruthenium sensitizer (dye 26) was also reported to enhance the light harvesting yield and thus produced $\mathrm{J}_{\mathrm{SC}}=18.3 \mathrm{~mA} / \mathrm{cm} 2$ [32]. A hybrid sensitizer containing carbazole-substituted triphenylamine linked with a terpyridyl ruthenium complex through a benzene bridge (dye 27) exhibited two broad absorption peaks from both the metal and organic sensitizer, along with an efficiency of $5.84 \%$ [33]. The combination of triphenylamine moieties and a cyclometalated ruthenium complex (dye 28) resulted in a broad and intense UV absorption peak extending beyond $800 \mathrm{~nm}$, with the highest efficiency reaching $8.02 \%$ [34]. The oxidation behavior of the sensitizer could be tuned by independently modulating the triphenylamine unit. Triphenylamine donor antennas were also used to replace the octyl chain of sensitizer Z907 to yield dye 29 and dye 30, which contributed to broad absorption and a $20 \%$ higher power conversion efficiency [35].

In addition, the introduction of an electron-donating phenothiazine group into an octylthiophenyl imidazophenanthroline-based ruthenium sensitizer (dye 31) was able to enhance the photovoltaic performance by improving the light harvesting ability, device resistance, and electron lifetime, showing efficiency of $9.1 \%$ compared to $8.8 \%$ for N3 [36]. Another type of ruthenium sensitizer consisting of carbazole-diazafluorene-based bipolar ancillary ligands has been developed [37]. The large dihedral angle between carbazole (electron donor) and 4,5-diazafluorene (electron acceptor) contributes to low MLCT bands and the localization of $\mathrm{HOMO}$ at an electron donor away from $\mathrm{TiO}_{2}$, resulting in an efficiency of $2.11 \%$ (dye 32). Further studies could benefit from the implication of this study in improvising the molecular architectures of metal hybrid sensitizers.

In short, the ancillary ligands of ruthenium sensitizers are still the main focus of study and development in the efforts to realize highly efficient DSSCs. In terms of bipyridine, terpyridine, and quarterpyridine ruthenium sensitizers, the introduction of bulky substituents containing a rich amount of electrons, with extended $\pi$ conjugation and hydrophobic moieties, produces highly efficient sensitizers. Cyclometalated ruthenium sensitizers and NCS-free ruthenium sensitizers are also gaining attention because the redox properties and electron distribution in the HOMO and LUMO states can be finely tuned by incorporating various kinds of substituents, which achieves high efficiency. Furthermore, hybrid sensitizers comprising a ruthenium framework with organic sensitizer ancillary ligands are successful and feasible sensitizers, which will open up a new direction in the development of metal complex sensitizers.

\section{Organic sensitizers}

Organic sensitizers are set apart from conventional sensitizers as metal-free-based sensitizers with comparative light-harvesting properties and photovoltaic performances, in addition to their highly tunable structures, which enable optimization according to several conditions, as well as modification, environmental concern, and low cost. Typical organic sensitizers consist of a donor- $\pi$ acceptor (D- $\pi-\mathrm{A})$ configuration that allows an intramolecular charge transfer (ICT) transition to take place. Organic sensitizers have also been synthesized in other configurations such as structures with auxiliary acceptors $(\mathrm{D}-\pi-\mathrm{A}-\pi-\mathrm{A}),(\mathrm{D}-\mathrm{A}-\pi-\mathrm{A})$, and auxiliary donors $(D-\pi-D-\pi-A),(D-D-A-\pi-A)$. Here, we review the recent modification and development of each segment (donor, $\pi$-linker, and acceptor) of the organic sensitizers. The absorption maxima and photovoltaic efficiencies of organic sensitizers are summarized in Table 2. The molecular structures of electron donor-modified sensitizers from dye 33 to dye 50 are displayed in Fig. 5, while the molecular structures of electron acceptor modified sensitizers from dye 51 to dye 59 are displayed in Fig. 6. The molecular structures of $\pi$-spacer modified sensitizers from dye 60 to dye 72 are displayed in Fig. 7, and the molecular structures of $\pi$-spacer modified sensitizers from dye 73 to dye 80 are displayed in Fig. 8.

\section{Electron donor}

The triphenylamine group is commonly employed as an electron donor because of its good solution-processability, efficient hole-transporting property, and ability to prevent direct charge recombination between $\mathrm{TiO}_{2}$ and $\mathrm{I}_{3}{ }^{-}$. Recently, triphenylamine-based organic sensitizers using benzimidazole derivatives as secondary donors were synthesized and characterized [38]. The introduction of benzimidazole and its dithiolethione derivatives into the framework of triphenylamine, as shown in dye 33 and dye 


\section{Advanced Materials Letters www. vbripress.com/aml}

34, respectively, enhanced the photogenerated charge separation and increased the molar extinction coefficient. Other triphenylamine-benzimidazole type organic sensitizers with an additional methoxy group (dye 35) were also synthesized [39]. The methoxy group increases the electron delocalization forming the intramolecular charge transfer, and giving an efficiency of $4.31 \%$. A propeller-shaped triphenylamine-based organic sensitizer (dye 36) with the ethynylphenyl bridge was investigated [40]. The unique orientation of the sensitizer could effectively prevent electron recombination and thus reached a $\mathrm{V}_{\mathrm{OC}}$ of $0.7 \mathrm{~V}$, which was comparable to that of N719. More recently, a new 3D triphenylamine electron donor group was developed for an organic sensitizer (dye 37 ) to resist the charge recombination and dark current in a DSSC [41]. The novel 3D sensitizer had a $21.1 \%$ higher efficiency than the conventional triphenylamine donor.

The benzimidazole group is a strong electron withdrawing group to improve the electron injection ability in the sensitization process. Methoxy- (dye 38) and N, Ndimethylamino- (dye 39) attached diphenyl-substituted benzimidazole organic sensitizers were synthesized and exhibited prolonged decay times in fluorescence [42]. The cell efficiency could be enhanced by attaching the methoxy moiety instead of the $\mathrm{N}, \mathrm{N}$-dimethylamine group, which may hamper the charge recombination process.

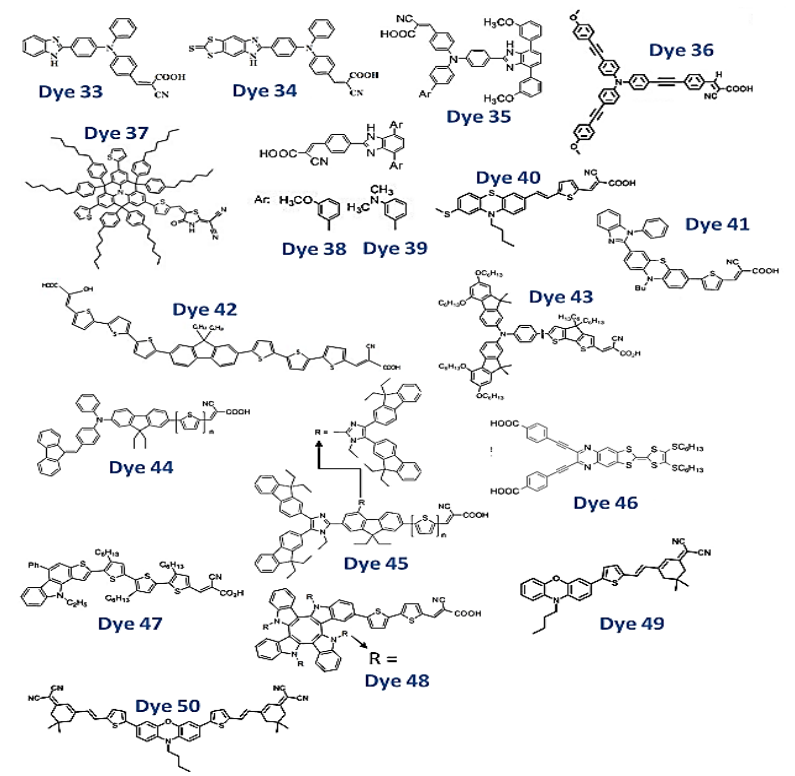

Fig. 5. Molecular structures of dye 33 and dye 34, Reproduced with permission from Ref. [38] (Copyright (2012) Elsevier); dye 35, reproduced with permission from Ref. [39] (Copyright (2015) Elsevier); dye 36, reproduced with permission from Ref. [40] (Copyright (2015) Elsevier); dye 37, reproduced with permission from Ref. [41] (Copyright (2017) Elsevier); dye 38 and dye 39, reproduced with permission from Ref. [42] (Copyright (2015) Elsevier); dye 40, reproduced with permission from Ref. [43] (Copyright (2012) The Royal Society of Chemistry); dye 41, reproduced with permission from Ref. [44] (Copyright (2014) The Royal Society of Chemistry); dye 42, reproduced with permission from Ref. [45] (Copyright (2011) Elsevier); dye 43, reproduced with permission from Ref. [46] (Copyright (2013) American Chemical Society); dye 44, reproduced with permission from Ref. [47] (Copyright (2014) The Royal Society of Chemistry); dye 45, reproduced with permission from Ref. [48] (Copyright (2014) American Chemical Society); dye 46, reproduced with permission from Ref. [49] (Copyright (2014) The Royal Society of Chemistry); dye 47, Reproduced with permission from Ref. [50] (Copyright (2015) Elsevier); dye 48, reproduced with permission from Ref. [51] (Copyright (2015) Elsevier); dye 49 and dye 50, reproduced with permission from Ref. [52] (Copyright (2014) The Royal Society of Chemistry).
Table 2. Reviewed organic sensitizers and their respective maximum absorption wavelengths, molar extinction coefficients, and PCEs.

\begin{tabular}{|c|c|c|c|c|c|c|}
\hline $\begin{array}{l}\text { Sensiti } \\
\text { zers }\end{array}$ & $\begin{array}{c}\text { Maximum absorption } \\
\left(\lambda_{\max }\right) / \mathrm{nm}[\mathrm{Molar} \text { extinction } \\
\left.\text { coefficient }(\varepsilon) / \mathbf{M}^{-1} \mathbf{c m}^{-1}\right]\end{array}$ & $\begin{array}{r}\mathrm{J}_{\mathrm{SC}} \\
(\mathbf{m A} \\
\left.\mathbf{c m}^{-2}\right)\end{array}$ & $\begin{array}{l}\text { Voc } \\
(\mathbf{V})\end{array}$ & FF & $\begin{array}{l}\text { PCE } \\
\text { (प) } \\
/ \%\end{array}$ & Ref. \\
\hline \multicolumn{7}{|c|}{ i) Electron donor } \\
\hline \multicolumn{7}{|c|}{ Triphenylamine } \\
\hline dye 33 & $421(48000)$ & 5.1 & 0.7 & 0.7 & 2.4 & \multirow[t]{2}{*}[38]{} \\
\hline dye 34 & $410(74900)$ & 6.1 & 0.7 & 0.6 & 2.7 & \\
\hline dye 35 & 428 & 9.0 & 0.7 & 0.6 & 4.3 & [39] \\
\hline dye 36 & - & 10.0 & 0.7 & 0.7 & 5.1 & [40] \\
\hline dye 37 & 377 (62534), 537 (46666) & 9.0 & 0.7 & 0.7 & 4.3 & [41] \\
\hline \multicolumn{7}{|c|}{ Benzimidazole } \\
\hline dye 38 & 360 & 5.7 & 0.7 & 0.7 & 2.7 & \multirow[t]{2}{*}[42]{} \\
\hline dye 39 & 360 & 5.3 & 0.6 & 0.6 & 2.1 & \\
\hline \multicolumn{7}{|c|}{ Phenothiazine } \\
\hline dye 40 & $478(29300)$ & 15.2 & 0.7 & 0.7 & 7.4 & [43] \\
\hline dye 41 & $\begin{array}{ll}302(35100), & 345(22300), \\
438(18400) & \end{array}$ & 9.1 & 0.6 & 0.7 & 3.7 & [44] \\
\hline \multicolumn{7}{|c|}{$\begin{array}{c}\text { Fluorene } \\
\end{array}$} \\
\hline dye 42 & $484(111900)$ & 12.3 & 0.6 & 0.6 & 4.7 & [45] \\
\hline dye 43 & $554(47500)$ & 16.2 & 0.8 & 0.8 & 10.3 & [46] \\
\hline dye 44 & $470(38800)$ & $\begin{array}{c}14,8 \\
0\end{array}$ & 0.7 & 0.6 & 6.1 & [47] \\
\hline dye 45 & $333(58000), 459(37900)$ & 7.9 & 0.6 & 0.7 & 3.3 & [48] \\
\hline \multicolumn{7}{|c|}{ Tetrathiafulvalene } \\
\hline dye 46 & $526(19000)$ & 13.8 & 0.6 & 0.8 & 6.5 & [49] \\
\hline \multicolumn{7}{|c|}{ Thieno[3,2-a]carbazole } \\
\hline dye 47 & $476(34,420)$ & 14.1 & 0.8 & 0.7 & 8.0 & [50] \\
\hline \multicolumn{7}{|c|}{ Tetraindole } \\
\hline dye 48 & $474(17100)$ & 13.0 & 0.8 & 0.7 & 6.5 & [51] \\
\hline \multicolumn{7}{|c|}{ Phenoxazine } \\
\hline dye 49 & $535(30800)$ & 10.5 & 0.8 & 0.4 & 3.6 & \multirow[t]{2}{*}{ [52] } \\
\hline dye 50 & $559(31400)$ & 13.1 & 0.9 & 0.5 & 5.6 & \\
\hline
\end{tabular}

ii) Electron acceptor
Pyridine, quinolone, pyrazine and quinoxaline

\begin{tabular}{|c|c|c|c|c|c|c|}
\hline dye 51 & 461 & 5.6 & 0.7 & 0.7 & 2.6 & \multirow[t]{2}{*}{ [54] } \\
\hline dye 52 & 508 & 11.5 & 0.7 & 0.8 & 6.6 & \\
\hline \multicolumn{7}{|c|}{ Rhodanine } \\
\hline dye 53 & $505(22600)$ & 11.8 & 0.6 & 0.6 & 4.5 & [55] \\
\hline \multicolumn{7}{|c|}{ Cyanoacetic acid, rhodanine-3-acetic acid and 4-aminobenzoic acid } \\
\hline dye 54 & $462(33,000)$ & 9.4 & 0.6 & 0.7 & 4.1 & [56] \\
\hline dye 55 & $449(14100)$ & 11.1 & 0.8 & 0.7 & 6.2 & [57] \\
\hline \multicolumn{7}{|c|}{ Pyridine-N-oxide } \\
\hline dye 56 & $405(34200)$ & 8.7 & 0.6 & 0.7 & 3.7 & [58] \\
\hline \multicolumn{7}{|c|}{ Pyridinium } \\
\hline dye 57 & $459(31000)$ & 8.9 & 0.6 & 0.7 & 3.9 & [59] \\
\hline \multicolumn{7}{|c|}{ Pyrido[3,4-b]pyrazine } \\
\hline dye 58 & $396(12400), 497(16800)$ & 12.1 & 0.7 & 0.8 & 6.1 & [60] \\
\hline dye 59 & 488,630 & 9.1 & 0.6 & 0.7 & 3.6 & [61] \\
\hline \multicolumn{7}{|c|}{ iii) ПI-spacer } \\
\hline \multicolumn{7}{|c|}{ Phenyl, thiophene and fluorine } \\
\hline dye 60 & $278(24900), 433(37200)$ & 9.5 & 0.5 & 0.7 & 3.3 & [62] \\
\hline \multicolumn{7}{|c|}{$\begin{array}{r}\text { Thiophene } \\
\end{array}$} \\
\hline dye 61 & $386(70900)$ & 10.8 & 0.7 & 0.7 & 5.7 & [63] \\
\hline \multicolumn{7}{|c|}{ Oligothiophene } \\
\hline dye 62 & $\begin{array}{l}343(\mathrm{sh}), 400(46600), 506 \\
(\mathrm{sh})\end{array}$ & 3.7 & 0.5 & 0.6 & 1.2 & [64] \\
\hline dye 63 & $\sim 375, \sim 498$ & 18.8 & 0.8 & 0.7 & 11.2 & [65] \\
\hline dye 64 & $312(32000), 497(18000)$ & 14.7 & 0.7 & 0.7 & 7.4 & [66] \\
\hline \multicolumn{7}{|c|}{$\begin{array}{r}\text { Cyanovinyl } \\
\end{array}$} \\
\hline dye 65 & $413(20739)$ & 7.5 & 0.6 & 0.6 & 3.5 & \multirow[t]{2}{*}{ [67] } \\
\hline dye 66 & $362(34505)$ & 3.5 & 0.6 & 0.7 & 1.6 & \\
\hline \multicolumn{7}{|c|}{ Diketopyrrolopyrrole } \\
\hline dye 67 & - & 15.6 & 0.7 & 0.7 & 7.7 & [68] \\
\hline \multicolumn{7}{|c|}{ Fluorene } \\
\hline dye 68 & $433(30000)$ & 8.2 & 0.7 & 0.7 & 4.3 & [69] \\
\hline dye 69 & $393(16233)$ & 7.8 & 0.7 & 0.7 & 3.5 & [70] \\
\hline dye 70 & $402(53957)$ & 8.2 & 0.6 & 0.6 & 3.1 & \multirow[t]{3}{*}{ [71] } \\
\hline dye 71 & $427(88752)$ & 10.8 & 0.7 & 0.6 & 4.6 & \\
\hline dye 72 & $436(97276)$ & 14.3 & 0.7 & 0.6 & 5.6 & \\
\hline dye 73 & $385(55300), 453(53900)$ & 12.7 & 0.7 & 0.6 & 5.0 & \multirow[t]{4}{*}{ [72] } \\
\hline dye 74 & $392(76200), 465(50200)$ & 13.3 & 0.6 & 0.6 & 5.3 & \\
\hline dye 75 & $380(50600), 458(32000)$ & 10.1 & 0.7 & 0.6 & 4.2 & \\
\hline dye 76 & $384(54500), 468(44200)$ & 12.5 & 0.6 & 0.6 & 5.0 & \\
\hline \multicolumn{7}{|c|}{ Benzothiadiazole } \\
\hline dye 77 & 540 & 12.0 & 0.5 & 0.7 & 4.0 & [73] \\
\hline \multicolumn{7}{|c|}{ Phenylenevinylene } \\
\hline dye 78 & $510(33113)$ & 11.6 & 0.8 & 0.8 & 7.1 & [74] \\
\hline \multicolumn{7}{|c|}{ Dithieno[2,3-d;2',3'-d']benzo[1,2-b;4,5-b']dithiophene } \\
\hline dye 79 & $485(34800)$ & 12.7 & 0.7 & 0.7 & 6.3 & [75] \\
\hline \multicolumn{7}{|c|}{ EDOT $\pi$-bridge } \\
\hline dye 80 & $562(56500)$ & 9.1 & 0.9 & 0.7 & 5.3 & [76] \\
\hline
\end{tabular}




\section{Advanced Materials Letters www. vbripress.com/aml}

Phenothiazine is known for its low oxidation potential, the formation of stable cations upon electron donation, and unique butterfly conformation, which hinders dye aggregation. In recent times, a simple organic sensitizer incorporating 10-butyl-(2-methylthio) -10H-phenothiazine as a donor group (dye 40) produced an efficiency of $6.53 \%$ [43]. Extending the sensitizer linker with thiophene led to an efficiency of $7.44 \%$. Replacing the phenothiazine donor with N-phenylbenzimidazole (dye 41) increased the molar extinction coefficient, electron recombination resistance, and electron lifetime [44].

Fluorene is an electron-rich moiety with a high structure rigidity, which enables efficient support, stabilizes photosensitized radicals, and modulates the excited state properties. A DSSC sensitized by a fluorene organic sensitizer (dye 42) showed an efficiency of $4.73 \%$ because of the high molar extinction coefficient [45]. A fluorene donor substituted with hexyloxy groups (dye 43) exhibited an exceptional electron-donating characteristic and electron recombination prevention with an efficiency of $10.3 \%$ [46]. Organic sensitizers with one fluorenylidene moiety introduced in the donor part of triarylamine (dye 44) generated a high efficiency of $6.13 \%$ [47]. On the other hand, an organic sensitizer containing fluorene functionalized with two imidazole chromophores as donors (dye 45) were synthesized [48]. The best performing DCCS was the one sensitized by the aminoimidazole unit, which enabled a higher loading of dye and bithiophene conjugation segment, which contained a richer electron density.

The tetrathiafulvalene group was also studied as an electron donor. A quinoxaline-fused tetrathiafulvalene based sensitizer with two conjugated electron donors in a Y-shaped structure (dye 46) has been synthesized [49]. The absorption spectra of the sensitizer covered the UV region out to the red range at around $610 \mathrm{~nm}$ because of the strong electronic transition. exhibiting an efficiency of $6.47 \%$.

Some other types of donors have been developed and introduced in organic sensitizers. A sensitizer with a thieno[3,2-a]carbazole donor (dye 47) achieved a high $\mathrm{V}_{\mathrm{OC}}(0.78 \mathrm{~V})$ due to the bulky hexyl chains of terthiophene, which reduced the charge recombination [50]. Organic sensitizers employing a saddle-shaped tetraindole donor (dye 48) were successfully designed and synthesized for DSSCs [51]. The saddle-shaped tetraindole unit was found to potentially suppress dye aggregation when absorbed on $\mathrm{TiO}_{2}$. Phenoxazine-based organic sensitizers in a D- $\pi$-A configuration (dye 49) and A- $\pi$-D- $\pi$-A configuration (dye 50) were synthesized and applied in small molecule organic solar cells [52]. The A- $\pi$-D- $\pi$-A type sensitizer was more promising, with an efficiency of $5.60 \%$ as a result of the improved light absorption.

In conclusion, sensitizers based on TPA, benzimidazole, phenothiazine, fluorene, tetrathiafulvalene, and their derivatives as electron donors have been developed. The incorporation of ancillary groups to the parent structure of organic sensitizers and sensitizer structure modification was done with the aim of increasing the molar extinction coefficient and inhibiting interfacial charge recombination. Organic sensitizers based on the indole, phenoxazine, and pyrazine groups have also been synthesized to achieve comparable photovoltaic performances. Moreover, it is crucial to study the intramolecular interaction between the electron donor group and electron acceptor group, as well as the $\pi$-bridge, which will generally dictate the photoelectron excitation and injection pathway.

\section{Electron acceptor}

Cyanoacrylate has been commonly assigned as the acceptor and anchoring group for D- $\pi$-A sensitizers because of the good spectral responses attributed to intramolecular charge transfer and its good electron injection properties [53]. Other types of acceptor groups have also been developed in order to achieve efficient electron injection like cyanoacrylate. Organic sensitizers incorporating pyridine (dye 51) and the pyrazine acceptor (dye 52) have been developed and studied [54]. It has been found that the low withdrawing strength of pyridine and the pyrazine acceptor acts as an efficient acceptor for a sensitizer, where $\mathrm{E}\left(\mathrm{S}+/ \mathrm{S}^{*}\right)$ is too low for strong withdrawing cyanoacrylate. The rhodanine unit used as an electron acceptor (dye 53) with an increase in methylene units could restrain the regeneration between excited electrons and the oxidized sensitizer [55]. Power efficiency of $4.12 \%$ was achieved for the 4-aminobenzoic acid unit in the D-D-A- $\pi$-A organic sensitizer (dye 54), which efficiently withdraws and injects an electron into the conduction band of $\mathrm{TiO}_{2}$, which leads to efficient charge generation, transport, and injection [56]. Using the rhodanine-3-acetic acid acceptor in the D- $\pi$-A organic sensitizer (dye 55) produced a maximum IPCE of $79 \%$ at $485 \mathrm{~nm}$ [57].

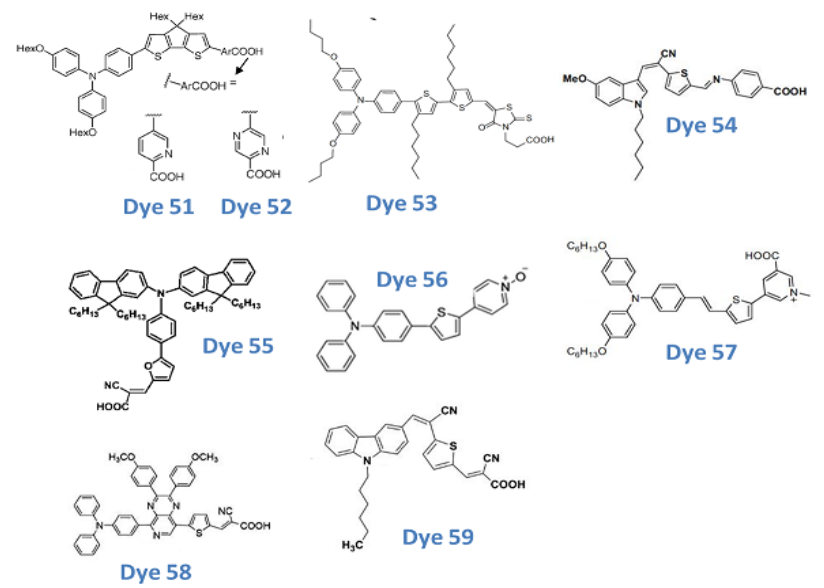

Fig. 6. Molecular structures of dye 51 and dye 52, reproduced with permission from Ref. [54] (Copyright (2012) The Royal Society of Chemistry); dye 53, reproduced with permission from Ref. [55] (Copyright (2013) The Royal Society of Chemistry); dye 54, reproduced with permission from Ref. [56] (Copyright (2015) Elsevier); dye 55, reproduced with permission from Ref. [57] (Copyright (2015) Elsevier); dye 56, reproduced with permission from Ref. [58] (Copyright (2013) The Royal Society of Chemistry); dye 57, reproduced with permission from Ref. [59] (Copyright (2012) The Royal Society of Chemistry); dye 58, reproduced with permission from Ref. [60] (Copyright (2013) The Royal Society of Chemistry); dye 59, reproduced with permission from Ref. [61] (Copyright (2017) Elsevier). 


\section{Advanced Materials Letters www. vbripress.com/aml}

DSSCs incorporating pyridine-based electron acceptors have also been studied recently, including pyridine-N-oxide (dye 56) [58], pyridinium (dye 57) [59], and pyrido[3,4-b]pyrazine (dye 58) [60]. The strong withdrawing characteristic of the pyridine-N-oxide unit yielded an efficiency of $3.72 \%$. Pyridium-based sensitizers exhibit maximum absorptions between $445 \mathrm{~nm}$ and 450 $\mathrm{nm}$, and the different position of the carboxyl anchoring group could exert a conjugated effect for excited electron injection. For pyrido[3,4-b]pyrazine-based organic sensitizers in the D-A- $\pi$-A configuration, methoxyphenylsubstituted pyrido[3,4-b]pyrazine improved the $\mathrm{J}_{\mathrm{SC}}$ and $\mathrm{V}_{\mathrm{OC}}$, rendering a two-fold improvement in efficiency to $6.14 \%$ compared to unsubstituted pyrido[3,4-b]pyrazine. More recently, a carbazole-based sensitizer with the D- $\pi-A-\pi-A$ architecture connected to cyanoacetic acid (dye 59) showed a photoconversion efficiency of 3.55\%, demonstrating the importance of using a cyanoacetic acid acceptor to improve the IPCE, $\mathrm{J}_{\mathrm{SC}}$, and power conversion efficiency [61].

In short, in addition to employing the classical cyanovinyl group as an electron acceptor, moieties such as pyridine, pyrazine, iso-quinoline, rhodamine, quinoxaline, pyridine-N-oxide, and the pyridium based unit were also developed and showed remarkable efficiencies. This made a wider variety of acceptor moieties available for the synthesis of organic sensitizers with high sensitizer loading abilities, less steric hindrance, and the ability to suppress sensitizer regeneration at the semiconductor surface.

\section{II-spacer}

Traditionally, polyaryl or heteroaryl $\pi$-conjugated spacers, including phenyl, oligothiophene, and fluorene, have been the candidates for $\pi$-spacers because the conjugated segment facilitates the charge transfer process. The oligothiophene segment is favorable for a charge transfer pyrene-based organic sensitizer (dye 60) because it forms a planar arrangement with the acceptor groups, securing facile extended conjugation [62]. The effect of varying the length of the thiophene conjugation in the $\pi$-linker on the cell performance was reported [63]. Higher efficiencies were shown on solar cells with bithiophene and thienylfluorene containing a sensitizer (dye 61). In anchoring organic sensitizers with the D-D- $\pi$-A and D-D$(\pi-\mathrm{A})^{2}$ configurations, bithiophene containing a sensitizer (dye 62) exhibited red-shifted absorption and a higher molar extinction coefficient than the monothiophene analog, indicating the importance of an electron-rich $\pi$ conjugation pathway [64]. On the other hand, an extensively conjugated tetrathienoacene $\pi$-spacer was utilized in an organic sensitizer with the branched alkyl analog (dye 63), achieving the highest efficiency of $11.18 \%$ because of the significant tilting and packing distortion on the $\mathrm{TiO}_{2}$ surface compared to the conventional ordered monolayer of a sensitizer [65].

The effect of conjugated side groups on the thiophene $\pi$-bridge in an organic sensitizer was also studied [66]. It was reported that the introduction of electron donating conjugate thiophene olefinin side groups (dye 64) could red shift the $\lambda \max$ and increase $\mathrm{J}_{\mathrm{SC}}$. A semi-rigid and bulky diene structure with existing steric hindrance could recede the ICT process and cause aggregation, which led to a lower sensitizer absorption and lower $\mathrm{J}_{\mathrm{SC}}$. On the other hand, the effect of the cyanovinyl $\pi$-bridge of a benzimidazole-based organic sensitizer on the photovoltaic performance was studied [67]. A sensitizer that contained the cyanovinyl unit (dye 65) showed more than double the power conversion efficiency than that without the cyanovinyl unit (dye 66). Showing the function of the cyanovinyl unit in reducing the bandgap, broadening the absorption spectra, and suppressing charge recombination.

On the other hand, an asymmetric organic sensitizer employing a thienyl-diketopyrrolopyrrole core as the spacer (dye 67) was synthesized and achieved an efficiency of $7.7 \%$ owing to the extended photocurrent linearity and maximal spectral response $[\mathbf{6 8}]$.

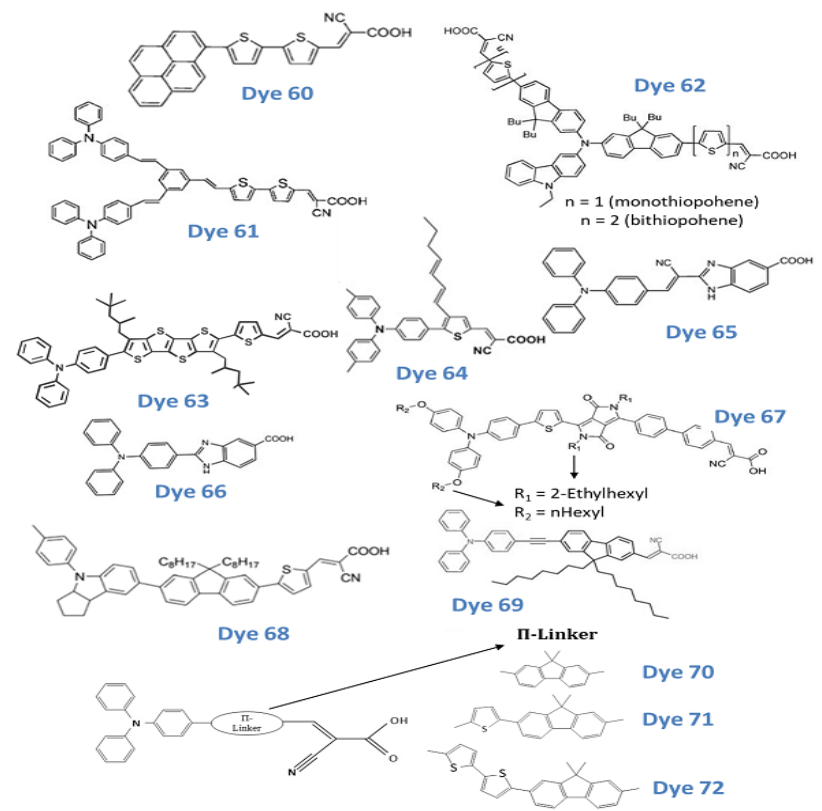

Fig. 7. Molecular structures of dye 60 , reproduced with permission from Ref. [62 (Copyright (2011) The Royal Society of Chemistry); dye 61, reproduced with permission from Ref. [63] (Copyright (2012) The Royal Society of Chemistry); dye 62, reproduced with permission from Ref. [64] (Copyright (2014) Wiley); dye 63, reproduced with permission from Ref. [65] (Copyright (2017) The Royal Society of Chemistry);dye 64, reproduced with permission from Ref. [66] (Copyright (2016) Elsevier); dye 65 and dye 66, reproduced with permission from Ref. [67] (Copyright (2014) Elsevier; dye 67, reproduced with permission from Ref. [68] (Copyright (2012) The Royal Society of Chemistry); dye 68, reproduced with permission from [69] (Copyright (2011) The Royal Society of Chemistry); dye 69, reproduced with permission from Ref. [70] (Copyright (2014) Elsevier); dye 70, dye 71 and dye 72, reproduced with permission from Ref. [71] (Copyright (2012) Wiley).

The fluorene moiety was also commonly employed as a conjugated $\pi$-bridge. The rigid and planar octylsubstituted fluorene linkage in dye 68 was found to be favorable for effective light harvesting [69]. Fluorene combined with acetylene moieties as the $\pi$-bridge in dye 69 produced an ideal electron transfer pathway upon excitation [70]. The elongation of the conjugation bridge could increase the molar extinction coefficient and reduce the interaction between the donor and acceptor, leading to a higher energy optical excitation. The fluorene unit 


\section{Advanced Materials Letters www. vbripress.com/aml}

coupled with thiophene as the conjugated spacer in dye 70 to dye 72 was reported [71]. It was shown that up to a marginal utility, elongating the conjugation length contributed to a higher sensitizer efficiency, whereas a further addition caused a decrease in efficiency. A recent report on $\pi-\mathrm{D}-\pi-\mathrm{D}-\pi-\mathrm{A}$ type anchoring organic sensitizers containing fluorene and oligothiophene units as connecting units (dye 73 to dye 76) showed that the longer bithiophene segment resulted in a smaller recombination resistance (Rrec) and electron lifetime, as well as a light harvesting capability [72].

There were also some electron-rich $\pi$-linkage moieties that have recently been utilized to develop highperformance DSSCs. The benzothiadiazole unit combined with thiophene as a conjugated spacer (dye 77) for a $\mathrm{ZnO}$ based DSSC displayed a higher efficiency than that of $\mathrm{TiO}_{2}$, which could be ascribed to a higher electron injection rate into the conduction band of $\mathrm{ZnO}$ [73]. The bulky carbon-bridged phenylenevinylene (CPV) linker with octyl side chains (dye 78) was effective in insulating the contact between $\mathrm{TiO}_{2}$ and the donor group, which suppressed the charge recombination process [74]. The rigidity of CPV-linked sensitizers played an important role in maintaining the lifetime of the sensitizer. Dithieno[2,3d;2',3'-d']benzo[1,2-b;4,5-b']dithiophene, which has excellent co-planarity and electron-rich properties, was utilized as the $\pi$-spacer in dye 79 , with broad absorption bands, high molar extinction coefficients, and an efficiency range of $6.32 \%$ [75]. A recent study on an organic sensitizer containing the EDOT $\pi$-bridge (dye 80 ) showed poor performance due to a significant twist in the molecular configuration between the EDOT and carboxylic acid, which retarded the intramolecular charge transfer process [76]. Hence, it was advised that the effect should be isolated from the general design of new dyes.

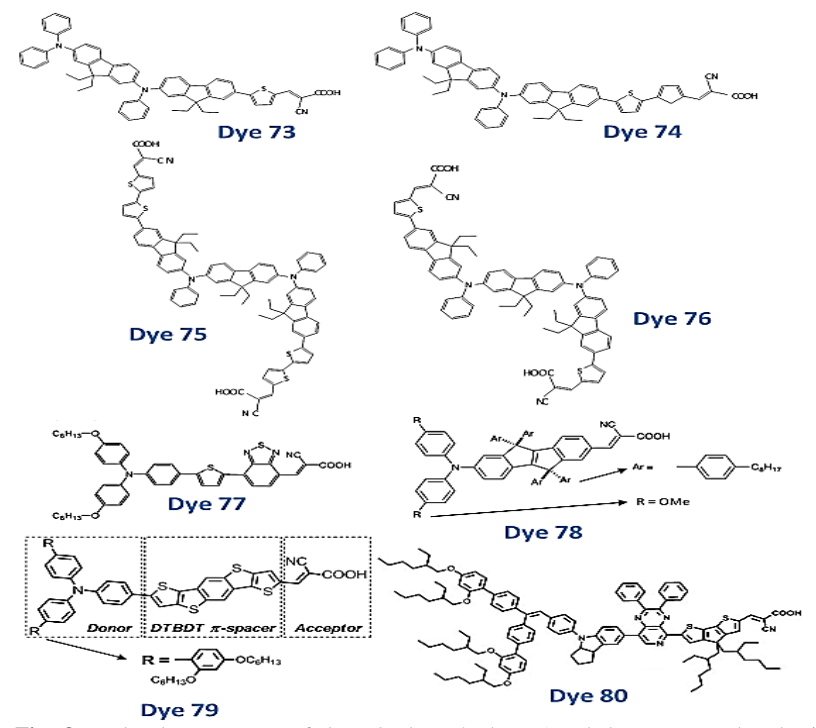

Fig. 8. Molecular structures of dye 73 , dye 74 , dye 75 and dye 76 , reproduced with permission from Ref. [72] (Copyright (2013) Elsevier); dye 77, reproduced with permission from Ref. [73] (Copyright (2012) The Royal Society of Chemistry); dye 78, reproduced with permission from Ref. [74] (Copyright (2012) The Royal Society of Chemistry); dye 79, reproduced with permission from Ref. [75] (Copyright (2014) The Royal Society of Chemistry); dye 80, reproduced with permission from Ref. [76] (Copyright (2017) The Royal Society of Chemistry).
As a whole, thiophene, fluorene, and diketopyrrolopyrrole-based $\pi$-conjugated spacers have been extensively developed and studies have generally concluded that the modification of the long $\pi$-conjugation bridge, as well as the introduction of a conjugation side chain into the framework of the $\pi$-bridge, is essential to improve the cell efficiency. However, there is a marginal unit where the elongation of the spacer could retard the interaction between the donor and acceptor. Apart from that, the application of a complex spacer with higher rigidity or a bulky size has also been attempted, and the $\pi$-linker was introduced, which exhibited strong photoelectrochemical properties for a DSSC sensitizer.

\section{Co-sensitization}

The co-sensitization strategy arises when the complementary absorption ranges of two sensitizers result in a broader absorption range and stronger absorption band compared to those of the individual sensitizers. Generally, co-sensitization methods for DSSCs include immersing the $\mathrm{TiO}_{2}$ photoanode in a mixture of two dyes (cocktail dyes) or in two separate sensitizer solutions consecutively (stepwise co-sensitization). This review discusses recent reports of the co-sensitization of DSSCs by the combination of two ruthenium complex sensitizers, the combination of a ruthenium complex sensitizer and an organic sensitizer, and the combination of two organic sensitizers. The absorption maxima and photovoltaic efficiencies of the co-sensitization systems are listed in Table 3. The molecular structures of the sensitizers from dye 81 to dye 88 , N719, black dye, coumarin 343, eosin-Y, and rubrene are displayed in Fig. 9.

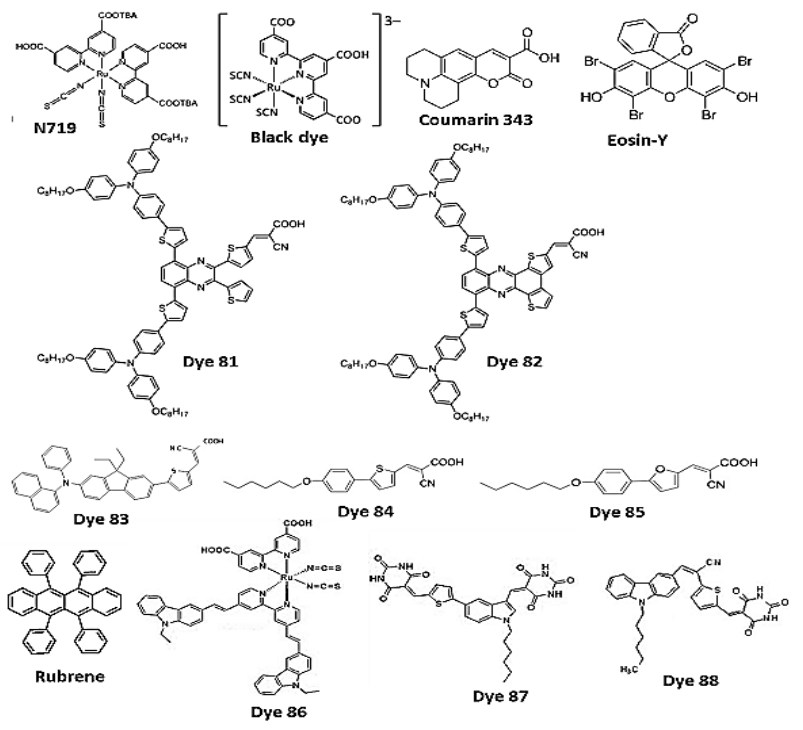

Fig. 9. Molecular structures of N719 and Black dye, reproduced with permission from Ref. [77] (Copyright (2011) Elsevier); Coumarin and Eosin-Y, reproduced with permission from Ref. [78] (Copyright (2016) Elsevier); dye 81 and dye 82, reproduced with permission from Ref. [79] (Copyright (2014) American Chemical Society); dye 83, reproduced with permission from Ref. [80] (Copyright (2011) Elsevier); dye 84 and dye 85 , reproduced with permission from Ref. [81] (Copyright (2016) Elsevier); coumarin 343 and eosin-Y, reproduced with permission from Ref. [78] (Copyright (2016) Elsevier); rubrene, reproduced with permission from Ref. [84] (Copyright (2015) Elsevier). dye 86 and dye 87, reproduced with permission from Ref. [85] (Copyright (2017) Elsevier). dye 88, reproduced with permission from Ref. [86]. (Copyright (2017) Elsevier). 
Table 3. Co-sensitization systems and corresponding PCE.

\begin{tabular}{|c|c|c|c|c|c|}
\hline Co-sensitization system & $\begin{array}{c}\mathbf{J s c} \\
\left(\mathbf{m A c m}{ }^{-2}\right)\end{array}$ & $\begin{array}{l}\text { Voc } \\
(\mathbf{V})\end{array}$ & FF & $\begin{array}{c}\text { PCE (n) } \\
/ \%\end{array}$ & Ref. \\
\hline \multicolumn{6}{|l|}{ i) Cocktail dye approach } \\
\hline \multicolumn{6}{|c|}{ Metal-metal co-sensitization } \\
\hline \multicolumn{6}{|c|}{$\mathrm{N3}+\mathrm{N719}$} \\
\hline 0.4 mM N719 + 0.1 mM N3 & 12.5 & 0.7 & 0.5 & 4.1 & [77] \\
\hline \multicolumn{6}{|c|}{$\begin{array}{l}\text { Organic-organic co-sensitization } \\
\end{array}$} \\
\hline \multicolumn{6}{|c|}{ Coumarin $343+$ Eosin-Y } \\
\hline Coumarin $343(\mathrm{C} 343)$ & 4.1 & 0.5 & 0.6 & 1.2 & \multirow{3}{*}{ [78] } \\
\hline Eosin-Y (EY) & 6.9 & 0.5 & 0.5 & 2.0 & \\
\hline $\mathrm{C} 343+\mathrm{EY}$ & 8.0 & 0.5 & 0.6 & 2.5 & \\
\hline \multicolumn{6}{|c|}{ Dithieno[2,3-a:3',2'-c]-phenazine- + Dithieno[2,3-a:3',2'-c]-quinaxaline } \\
\hline dye $81 /$ dye $82(8: 2)$ & 18.1 & 0.6 & 0.7 & 8.0 & [79] \\
\hline \multicolumn{6}{|c|}{ ii) Stepwise co-sensitization approach } \\
\hline \multicolumn{6}{|c|}{$\begin{array}{l}\text { Metal-organic co-sensitization } \\
\end{array}$} \\
\hline \multicolumn{6}{|c|}{ N719/black dye + Phenylamine } \\
\hline N719 & 10.5 & 0.8 & 0.6 & 4.9 & \multirow{11}{*}{ [80] } \\
\hline Black dye & 7.6 & 0.7 & 0.5 & 2.7 & \\
\hline dye 83 & 6.4 & 0.7 & 0.6 & 2.7 & \\
\hline $\mathrm{N} 719(10 \mathrm{~min}) /$ dye $83(5 \mathrm{~min})$ & 8.7 & 0.7 & 0.6 & 3.3 & \\
\hline N719 $(10 \mathrm{~min}) /$ dye $83(10 \mathrm{~min})$ & 8.9 & 0.7 & 0.6 & 4.0 & \\
\hline N719 $(10 \mathrm{~min}) /$ dye $83(20 \mathrm{~min})$ & 8.6 & 0.7 & 0.6 & 3.9 & \\
\hline N719 $(10 \mathrm{~min}) /$ dye $83(10 \mathrm{~min})$ & 9.7 & 0.7 & 0.6 & 4.3 & \\
\hline $\mathrm{N} 719(20 \mathrm{~min}) /$ dye $83(10 \mathrm{~min})$ & 11.4 & 0.7 & 0.6 & 5.1 & \\
\hline Black dye $(10 \mathrm{~min}) /$ dye $83(10 \mathrm{~min})$ & 8.1 & 0.7 & 0.6 & 3.1 & \\
\hline Black dye $(20 \mathrm{~min}) /$ dye $83(10 \mathrm{~min})$ & 9.8 & 0.7 & 0.6 & 3.8 & \\
\hline Black dye $(40 \mathrm{~min}) /$ dye $83(10 \mathrm{~min})$ & 8.7 & 0.6 & 0.6 & 3.1 & \\
\hline \multicolumn{6}{|c|}{ N719+ Phenyl } \\
\hline dye 84 & 3.9 & 0.7 & 0.7 & 1.2 & \multirow{5}{*}{ [81] } \\
\hline dye 85 & 5.0 & 0.7 & 0.7 & 2.6 & \\
\hline N719 & 16.9 & 0.7 & 0.7 & 7.9 & \\
\hline N719+dye 84 & 17.7 & 0.7 & 0.7 & 8.6 & \\
\hline N719+dye 85 & 17.6 & 0.8 & 0.7 & 9.0 & \\
\hline \multicolumn{6}{|c|}{ N3 + Rhodamine 19} \\
\hline RhCL & 4.2 & 0.5 & 0.3 & 0.6 & \multirow{3}{*}{ [82] } \\
\hline N3 & 7.0 & 0.6 & 0.5 & 2.4 & \\
\hline $\mathrm{N} 3+\mathrm{RhCL}$ & 11.0 & 0.7 & 0.6 & 4.7 & \\
\hline \multicolumn{6}{|c|}{ N719 + Rhodamine 19} \\
\hline N719 & 8.4 & 0.7 & 0.6 & 3.8 & \multirow{2}{*}{ [83] } \\
\hline N719+RhCL & 10.5 & 0.7 & 0.7 & 5.3 & \\
\hline \multicolumn{6}{|c|}{ N719 + Rubrene } \\
\hline N719 & 14.3 & 0.7 & 0.6 & 5.5 & \multirow{3}{*}{ [84] } \\
\hline Rubrene/N719 (stepwise) & 18.7 & 0.7 & 0.6 & 7.6 & \\
\hline Rubrene/N719 (cocktail) & 17.4 & 0.7 & 0.6 & 7.1 & \\
\hline $0.2 \mathrm{mM}$ dye 86 & 24.4 & 0.7 & 0.6 & 10.3 & \multirow[b]{2}{*}{ [85] } \\
\hline $\begin{array}{l}0.2 \mathrm{mM} \text { dye } 86+0.2 \mathrm{mM} \text { dye } 87 \\
+20 \mathrm{mM} \text { CDCA }\end{array}$ & 25.1 & 0.7 & 0.6 & 10.7 & \\
\hline $\begin{array}{l}0.2 \mathrm{mM} \text { dye } 86+0.3 \mathrm{mM} \text { dye } 88 \\
+20 \mathrm{mM} \text { CDCA }\end{array}$ & 19.9 & 0.7 & 0.7 & 3.8 & [86] \\
\hline
\end{tabular}

\section{Cocktail dyes}

The cocktail dye co-sensitization approach in this review involves metal-metal and organic-organic systems. An approach to co-sensitize mesoporous hybrid $\mathrm{TiO}_{2}$-multiwalled carbon nanotube $\left(\mathrm{TiO}_{2}-\mathrm{MWCNT}\right)$ film with a cocktail dye of N3 and N719 was reported [77]. The cosensitization of the optimization concentrations of $\mathrm{N} 3$ and N719 significantly boosted the DSSC efficiency to $4.10 \%$ from $3.51 \%$ (N719) and 3.69\% (N3), respectively, which resulted in broader and more intense absorption spectra. The co-sensitization of cocktail dyes also induces a higher surface coverage on the $\mathrm{TiO}_{2}$ surface and decreases the recombination rate. Next, the combination of coumarin 343 and eosin-Y in an organic-organic blended sensitizer system was reported to sensitize DSSCs with an improved $\mathrm{J}_{\mathrm{SC}}$ and a longer electron lifetime, contributing to a power conversion efficiency of $2.45 \%$ [78]. Another cosensitization system with the dithieno[2,3-a:3',2'-c]quinaxaline-(dye81) and dithieno[2,3-a:3',2'-c]-phenazinecontaining organic sensitizer (dye 82) was studied [79].
The coplanar dithieno[2,3-a:3',2'-c] phenazine core possesses a stronger absorption at $629 \mathrm{~nm}$ and cosensitization by the dithieno[2,3-a:3',2'-c] quinoxaline unit causes the absorption valley at around $500 \mathrm{~nm}$ to be compensated.

\section{Stepwise co-sensitization}

The stepwise co-sensitization approach involves metalorganic and organic-organic systems. A stepwise cosensitization approach for a phenylamine-based organic sensitizer (dye 83) and N719 or black dye was shown to improve the cell performance [80]. Controlled distribution of N719 or black dye at the outer layer, with the organic sensitizer in the inner layer was observed, forming a twolayer-like $\mathrm{TiO}_{2}$ film rendering efficiencies of $5.10 \%$ and $3.78 \%$ respectively. Furthermore, the organic sensitizers of dye 84 and dye 85 can fill in the interstitial sites between the larger-sized N719 to impede the percolating $\mathrm{I}_{3}{ }^{-}$to $\mathrm{TiO}_{2}$ in a co-sensitization system. The stepwise cosensitization system yields an improved $\mathrm{J}_{\mathrm{SC}}$ and $\mathrm{V}_{\mathrm{OC}}$ as well as better efficiency compared to the single sensitizer analogs [81]. In another study, rhodamine 19 perchlorate mixed with $\mathrm{N} 3$ as a mixture sensitizer system was investigated to enhance the DSSC overall efficiency through high coverage and dense packing through the treatment of $\mathrm{TiO}_{2}$ with formic acid, and thus improve the light absorption [82]. Rhodamine 19 perchlorate was also applied in a co-sensitization system with N719 on a carboxylic acid treated electrode [83]. After being cosensitized in a stepwise manner, the co-sensitization system successfully improved the efficiency from $3.8 \%$ to $5.3 \%$ due to increased $\mathrm{J}_{\mathrm{SC}}$ and IPCE. On the other hand, a metal complex-organic sensitizer co-sensitization system containing rubrene and N719 was investigated [84]. Generally, rubrene could promote higher electron transfer, suppress charge recombination, and elongate the electron lifetime, which eventually led to a $40 \%$ increase in efficiency. A new bi-anchoring indole-based organic sensitizer with the A- $\pi$-D-A architecture (dye 87) acted as the co-sensitizer for a ruthenium-based sensitizer (dye 86) and significantly improved the light harvesting ability, showing a maximum efficiency of $10.68 \%$, and indicating the potential of bi-anchoring molecules in device performance enhancement [85]. Next, the co-sensitization of a carbazole-based organic sensitizer (dye 88) and ruthenium sensitizer was able to enhance the fill factor and thus improve the efficiency to $3.8 \%$. The electron withdrawing nature of barbituric acid in the carbaozle organic sensitizer implied its high potential in improving the efficiency of DSSCs [86].

A comparison between the cocktail dye approach and stepwise co-sensitization approach for rubrene-N719 cosensitization was done, and it was inferred that the cocktail dye was in inferior to the stepwise approach mainly due to the competition between rubrene and N719 causing a low absorption amount of rubrene on the $\mathrm{TiO}_{2}$ surface. Meanwhile, in the stepwise co-sensitization 


\section{Advanced Materials Letters www. vbripress.com/aml}

approach, rubrene was first fully adsorbed on the $\mathrm{TiO}_{2}$ surface followed by N719, which ensured a higher loading amount than the cocktail dye approach.

In conclusion, various co-sensitization systems are continuously being developed to achieve the ideal combination of complementary sensitizers to absorb a broader light spectrum and thus extend beyond the $\mathrm{J}_{\mathrm{SC}}$ limitation of a single sensitizer. Luminol compounds such as rubrene and rhodamine were applied as co-sensitizers for DSSCs and delivered a comparable overall efficiency. It was also found that among the two approaches proposed, stepwise co-sensitization is more effective than cocktail dye in terms of dye loading forming a densely packed monolayer on the $\mathrm{TiO}_{2}$ surface favorable for increased light absorption and inhibiting charge recombination.

\section{Recommendation / future work}

The ruthenium complex sensitizer is always a candidate to produce a high performing DSSC. There has been a wide range of studies conducted on the ruthenium sensitizer to improve the current results. However, concerns about environmental issues and the awareness of green energy have arisen, and the idea of producing green energy products that feature high efficiency and environmental friendliness is getting attention. Hence, despite ruthenium complexes being intensively developed in the past two decades as the best performing DSSC sensitizers, their relatively high production cost and negative effects on the environment have prompted the emergence and development of metal-free organic-based sensitizers. The advantages of organic-based sensitizers, such as their low production cost and environmentally friendly synthesis process, enable large-scale production and real-life application of DSSCs. Furthermore, organic sensitizers are more accessible to various modifications in molecular engineering, whereby the core structures and electron donors, electron acceptors, and $\pi$-spacers can be functionalized and optimized to improve the structureperformance relationship. Therefore, organic sensitizers would be the main subject of study in the photo-energy conversion society. Recently, organic photovoltaic (OPV) solar cells and perovskite solar cells have been under research as an alternative to DSSCs [87]. Particularly, OPV solar cells that are ultrathin, highly flexible, and lightweight are promising candidates for applications in electronic textiles, synthetic skin, and robotics, in addition to their comparable power conversion efficiency.

Co-sensitization is one of the strategies to improve the photovoltaic performance of a single sensitizer by compensating the absorption valley using a complementary sensitizer. Even though a co-sensitization system gives a positive result in efficiency, their feasibility in practical uses requires further optimization considering the cost of the sensitizers and the sensitization procedure and time, which could limit the focus of study in this category in the future. As a whole, the future prospects for thin film solar cell development will be directed toward achieving a low manufacturing cost, feasible real-life application, and minimum environmental pollution, while maintaining high performance.

\section{Conclusion}

The structural modification had been done on ruthenium polypyridyl sensitizers based on conventional ruthenium sensitizers in an effort to further enhance their performance and overcome their shortcomings. Cyclometalated, NCS-free, and metal-organic hybrid products of ruthenium complexes have been developed to improve the thermal stability while maintaining the efficiency of NCS-containing ruthenium polypyridyl complexes.

On the other hand, a new series of organic moieties capable of harvesting light at broader wavelengths have also been prepared and incorporated into the new molecular designs to create new types of high-efficiency DSSC sensitizers. Structure designs and modifications on the electron donor, electron acceptor, and $\pi$-spacer provide insight on the structural features of high performing organic sensitizers, which can effectively prevent charge recombination, harvest a broad light spectrum through the elongation of the $\pi$-conjugation and introduction of electron rich moieties, effectively improve dye loading on mesoporous, and prevent charge aggregation. Some of the sensitizers reviewed have reached the efficiency of commercial sensitizers, while even outperform them. Furthermore, it was suggested that organic-based sensitizers could arise as the main research topic in the future because they are suitable candidates for highperformance DSSCs with green energy.

A co-sensitization system of two sensitizers in a DSSC enables better performances through stronger light absorption at a broader range. The co-sensitization between ruthenium sensitizers and organic sensitizers with a stepwise approach stands out among the co-sensitization systems studied, and more studies should be done on different organic sensitizers and the dye loading optimization of each co-sensitizer.

In summary, the recent development of the sensitizers for DSSCs shows that the on-going work has focused on modifying typical molecular moieties to enhance the photovoltaic properties of the sensitizers. These efforts will continue to develop better sensitizers with easier synthesis methods, facile functionality, and high stability (up to $1000 \mathrm{~h}$ ) without sacrificing the excellent photovoltaic performance.

\section{Acknowledgement}

This research work was supported by FRGS MRSA (UPM/7002/1/FRGS/MRSA/5524986) from the Ministry of Education of Malaysia.

\section{Keywords}

DSSC, dye, sensitizer, ruthenium, organic, co-sensitization.

Received: 07 March 2019

Revised: 22 May 2019

Accepted: 25 May 2019 


\section{References}

1. O'regan, B.; Grätzel, M.; Nature; 1991, 353, 737.

2. Polo, A.S.; Itokazu, M.K.; Murakami Iha, N.Y.; Coord. Chem. Rev; 2004, 248, 1343

3. Archer, M. D.; Nozik, A. J.; Nanostructured and photoelectrochemical systems for solar photon conversion, World Scientific, 2008.

4. Rees, T. W.; Baranoff, E.; Polyhedron, 2014, 82, 37.

5. Wang, P.; Zakeeruddin, S. M.; Comte, P.; Exnar, I.; Grätzel, M.; J. Am. Chem. Soc., 2003, 125, 1166.

6. Nazeeruddin, M.K.; Pechy, P.; Renouard, T.; Zakeeruddin, S. M.; HumphryBaker, R.; Comte, P.; Liska, P.; Cevey, L.; Costa, E.; Shklover, V.; J. Am. Chem. Soc., 2001, 123, 1613.

7. Nazeeruddin, M. K.; Pechy, P.; Grätzel, M.; Chem. Commun., 1997, 1705.

8. Ci, Z.; Yu, X.; Wang, C.; Ma, T.; Bao, M.; Dyes Pigm., 2014, 104, 8

9. Wang, P.; Humphry-Baker, R.; Moser, J. E.; Zakeeruddin, S. M.; Grätzel, M; Chem. Mater., 2004, 16, 3246.

10. Klein, C.; Nazeeruddin, M. K.; Liska, P.; Di Censo, D; Hirata, N; Palomares, E; Durrant, J.; Grätzel, M.; Inorg. Chem., 2005, 44, 178 .

11. Yu, Z.; Najafabadi, H. M.; Xu, Y.; Nonomura, K.; Sun, L.; Kloo, L.; Dalton Trans., 2011, 40, 8361

12. Garcia-Iglesias, M.; Pelleja, L.; Yum, J. H.; Gonzalez-Rodriguez, D.; Nazeeruddin, M. K.; Gratzel, M.; Clifford, J. N.; Palomares, E.; Vazquez, P.; Torres, T.; Chem. Sci. 2012, 3, 1177.

13. Lobello, M.G.; Wu, K.L.; Reddy, M.A.; Marotta, G.; Gratzel, M.; Nazeeruddin, M. K.; Chi, Y.; Chandrasekharam, M.; Vitillaro, G.; De Angelis, F.; Dalton Trans., 2014, 43, 2726.

14. Sygkridou, D.; Sahin, C.; Varlikli, C.; Stathatos, E.; Elect. Acta, 2015, 160,227.

15. Cisneros, R.; Beley, M; Lapicque, F.; Gros, P. C.; Eur. J. Inorg. Chem., 2016, 2016, 33.

16. Ni, J. S.; Ho, K. C.; Lin, K. F.; J. Mater. Chem. A, 2013, 1, 3463.

17. Giribabu, L.; Bessho, T.; Srinivasu, M.; Vijaykumar, C.; Soujanya, Y.; Reddy, V.G.; Reddy, P. Y.; Yum, J.H.; Gratzel, M., Nazeeruddin; M.K.; Dalton Trans. 2011, 40, 4497 .

18. Islam, A.; Singh, S.P.; Yanagida, M; Karim, M.R.; Han, L; Int. J. Photoenergy, 2011, 2011.

19. Ozawa, H.; Fukushima, K; Urayama, A; Arakawa, H; Inorg. Chem., 2015, 54, 8887.

20. Chen, W.C.; Kong, F.T.; Ghadari, R.; Li, Z.Q.; Liu, X.P.; Yu, T.; Huang, Y.; Huang, Y.; Hayat, T.; Dai, S.Y.; The Journ. of Phys. Chem. C, 2017, 121, 8752

21. Abbotto, A.; Sauvage, F.; Barolo, C.; De Angelis, F.; Fantacci, S; Graetzel, M Manfredi, N; Marinzi, C.; Nazeeruddin, M.K.; Dalton Trans., 2011, 40, 234.

22. Pogozhev, D. V.; Bezdek, M. T. Z.; Schauer, P. A.; Berlinguette, C. P.; Inorg. Chem., 2013, 52, 3001.

23. Chen, H. S.; Chang, W. C.; Su, C.; Li, T. Y.; Hsu, N. M.; Tingare, Y. S.; Li, C.Y.; Shie, J. H.; Li, W.R.; Dalton Trans., 2011, 40, 6765.

24. Kaneko, R.; Wu, G.; Sugawa, K.; Otsuki, J.; Islam, A.; Han, L.; Bedja, I; Gupta, R. K.; J. Organomet. Chem., 2017, 833, 61.

25. Aghazada, S.; Ren, Y.; Wang, P.; Nazeeruddin, M. K.; Inorg. Chem., 2017, 56, 13437.

26. Wang, S.W.; Wu, K.L.; Ghadiri, E.; Lobello, M.G.; Ho, S.T.; Chi, Y.; Moser, J. E.; De Angelis, F.; Grätzel, M.; Nazeeruddin, M.K.; Chem. Sc., 2013, 4, 2423.

27. GraziaáLobello, M., Angelis, F.; Dalton Trans., 2015.

28. Wu, G.; Kaneko, R.; Zhang, Y.; Shinozaki, Y.; Sugawa, K.; Islam, A.; Han, L.; Bedja, I; Gupta, R. K.; Shen, Q.; Otsuki, J.; J. Power Sources, 2016, 307, 416.

29. Li, G., Hu, K., Robson, K. C., Gorelsky, S. I., Meyer, G. J., Berlinguette, C. P.; Shatruk, M.; Chem. Eur. J., 2015, 21, 2173.

30. Medved'ko, A. V.; Ivanov, V. K.; Kiskin, M. A.; Sadovnikov, A. A.; Apostolova, E. S.; Grinberg, V. A.; Emets, V. V.; Chizhov, A. O.; Nikitin, O. M.; Magdesieva, T. V.; Kozyukhin, S. A.; Dyes Pigm., 2017, 140, 169.

31. Dai, F. R.; Wu, W. J.; Wang, Q. W.; Tian, H.; Wong, W. Y.; Dalton Trans., 2011, 40, 2314

32. Yum, J.H.; Moon, S.J.; Karthikeyan, C.S.; Wietasch, H.; Thelakkat, M.; Zakeeruddin, S.M.; Nazeeruddin, M.K.; Grätzel, M.; Nano Energy, 2012, 1, 6.

33. Su, P. Y.; Liu, J. M.; Lin, X. L.; Chen, Y. F.; Xiao, L. M.; Kuang, D. B.; Su, C. Y.; Inorg. Chem. Front. 2015.

34. Robson, K. C.; Koivisto, B. D.; Yella, A.; Sporinova, B.; Nazeeruddin, M. K.; Baumgartner, T.; Grätzel, M.; Berlinguette, C.P.; Inorg. Chem., 2011, 50, 5494

35. Cao, K., Lu, J., Cui, J., Shen, Y., Chen, W., Alemu, G.; Wang, Z; Yuan, H; Xu, J.; Wang, M.; J. Mater. Chem. A, 2014, 2, 4945.

36. Yin, J. F.; Chen, J. G.; Lin, J. T. S.; Bhattacharya, D; Hsu, Y. C.; Lin, H. C.; Ho, K.C.; Lu, K. L.; J. Mater. Chem., 2012, 22, 130.

37. Sivakumar, R.; Recabarren, R; Ramkumar, S.; Manivel, A.; Alzate-Morales, J.; Contreras, D.; Manidurai, P.; New J. Chem., 2017.

38. Zhou, L.; Jia, C.; Wan, Z.; Li, Z.; Bai, J.; Zhang, L.; Zhang, J.; Yao, X.; Dyes Pigm., 2012, 95, 743.

39. Dinçalp, H.; Saltan, G. M.; Aykut, D.; Zafer, C.; Spectrochim. Acta, Part A, $\mathbf{2 0 1 5}, 149,157$.

40. Vinayak, M. V.; Lakshmykanth, T. M.; Yoosuf, M.; Soman, S.; Gopidas, K. R.; Sol. Energy, 2016, 124, 227.

41. Zhao, D.X.; Bian, L.Y.; Luo, Y.X.; Zhang, M.D.; Cao, H.; Chen, M.D.; Dyes Pigm., 2017, 140, 278.

42. Saltan, G. M.; Dinçalp, H.; Kıran, M.; Zafer, C.; Erbaş, S. C.; Mater. Chem. Phys., 2015, 163, 387.
43. Marszalek, M.; Nagane, S; Ichake, A.; Humphry-Baker, R.; Paul, V.; Zakeeruddin, S. M.; Gratzel, M.; J. Mater. Chem., 2012, 22, 889.

44. Bodedla, G.B.; Thomas, K.R.J.; Li, C.T.; Ho, K.C.; RSC Adv., 2014, 4, 53588

45. Sahu, D.; Padhy, H.; Patra, D.; Yin, J. F.; Hsu, Y. C.; Lu, K. L.; Wei, K. H. Lin, H. C.; Tetrahedron, 2011, 67, 303.

46. Yella, A.; Humphry-Baker, R.; Curchod, B. F.; Ashari Astani, N.; Teuscher, J. 1.; Polander, L. E.; Mathew, S.; Moser, J. E.; Tavernelli, I.; Rothlisberger, U.; Chem. of Mater., 2013, 25, 2733.

47. Baheti, A.; Justin Thomas, K. R.; Lee, C.P.; Li, C.T.; Ho, K.C.; J. of Mater Chem. A, 2014, 2, 5766 .

48. Kumar, D.; Justin Thomas, K.; Lee, C.P.; Ho, K.C.; The J. of Org. Chem., 2014, 79, 3159

49. Amacher, A.; Yi, C.; Yang, J.; Bircher, M. P.; Fu, Y.; Cascella, M.; Gratzel M.; Decurtins, S.; Liu, S. X.; Chem. Comm., 2014, 50, 6540.

50. Jiang, H.; Oniwa, K.; Islam, A.; Zhao, J.; Han, L.; Sun, Y.J.; Bao, M.; Asao, N.; Yamamoto, Y.; Jin, T.; Tetrahedron, 2015, 71, 6534.

51. Qian, X.; Gao, H.H.; Zhu, Y.Z.; Pan, B.; Zheng, J.Y.; Dyes \& Pigm., 2015, $121,152$.

52. Cheng, M.; Yang, X.; Chen, C.; Tan, Q.; Sun, L.; J. of Mater. Chem. A, 2014 2,10465 .

53. Wiberg, J.; Marinado, T.; Hagberg, D. P.; Sun, L.; Hagfeldt, A.; Albinsson, B The J. of Phys. Chem. C, 2009, 113, 3881 .

54. Delcamp, J. H.; Yella, A.; Nazeeruddin, M. K.; Gratzel, M.; Chem. Comm. 2012, 48, 2295

55. Zhao, J.; Yang, X.; Cheng, M.; Wang, W.; Sun, L.; RSC Adv., 2014, 4, 4811.

56. Babu, D. D.; Cheema, H.; Elsherbiny, D.; El-Shafei, A.; Adhikari, A. V.; Electro. Acta, 2015, 176, 868

57. Gupta, K.; Singh, S. P.; Islam, A.; Han, L.; Chandrasekharam, M.; Electro. Acta, 2015, 174, 581 .

58. Wang, L.; Yang, X.; Li, S.; Cheng, M.; Sun, L.; RSC Adv., 2013, 3, 13677.

59. Tian, J.; Yang, X.; Zhao, J.; Wang, L.; Wang, W.; Li, J.; Sun, L.; RSC Adv., 2014, 4, 34644 .

60. Ying, W.; Yang, J.; Wielopolski, M.; Moehl, T.; Moser, J.E.; Comte, P.; Hua, J.; Zakeeruddin, S. M.; Tian, H.; Gratzel, M.; Chem. Sci., 2014, 5, 206.

61. Naik, P.; Elmorsy, M. R., Su, R.; Babu, D. D.; El-Shafei, A.; Adhikari, A. V.; Sol. Ener., 2017, 153, 600.

62. Baheti, A.; Lee, C. P.; Thomas, K. R. J.; Ho, K. C.; Phys. Chem. Chem. Phys. 2011, 13, 17210 .

63. Chang, D.W.; Tsao, H.N.; Salvatori, P.; De Angelis, F.; Gratzel, Park, M.S.M. Dai, L.; Lee, H. J.; Baek, J. B.; Nazeeruddin, M. K.; RSC Adv., 2012, 2, 6209.

64. Baheti, A.; Justin Thomas, K., Lin, L. C.; Lee, K. M.; Asian. J. of Org. Chem. 2014, 3, 886

65. Ezhumalai, Y.; Lee, B.; Fan, M.S.; Harutyunyan, B.; Prabakaran, K.; Lee, C.P.; Chang, S. H.; Ni, J.S.; Vegiraju, S.; Priyanka, P.; J. of Mater. Chem. A, 2017, 5 , 12310.

66. Long, J.; Liu, X.; Guo, H.; Zhao, B.; Tan, S.; Dyes \& Pigm., 2016, 124, 222.

67. Manoharan, S.; Anandan, S.; Dyes \& Pigm., 2014, 105, 223.

68. Yum, J. H.; Holcombe, T. W.; Kim, Y.; Yoon, J. ; Rakstys, K.; Nazeeruddin, M. K.; Gratzel, M.; Chem. Comm., 2012, 48, 10727.

69. Li, W.; Wu, Y. Li, X.; Xie, Y.; Zhu, W.; Ener. \& Envir. Sci., 2011, 4, 1830.

70. Tigreros, A.; Dhas, V.; Ortiz, A.; Insuasty, B.; Martín, N.; Echegoyen, L.; Sol. Ener. Mater. and Sol. Cells, 2014, 121, 61.

71. Wu, C. G.; Chung, M. F.; Tsai, H. H. G.; Tan, C. J.; Chen, S. C.; Chang, C. H.; Shih, T. W.; ChemPlusChem, 2012, 77, 832.

72. Baheti, A.; Thomas, K. J.; Lee, C. P.; Ho, K. C.; Org. Electr., 2013, 14, 3267.

73. Lin, R. Y. Y.; Lee, C. P.; Chen, Y. C.; Peng, J. D.; Chu, T. C.; Chou, H. H.; Yang, H. M.; Lin, J. T.; Ho, K. C.; Chem. Comm., 2012, 48, 12071.

74. Zhu, X.; Tsuji, H.; Yella, A.; Chauvin, A. S.; Gratzel, M.; Nakamura, E.; Chem. Comm., 2013, 49, 582.

75. Guo, X.; Tsao, H. N.; Gao, Xia, D.; An, C.; Nazeeruddin, M. K.; Baumgarten, M.; Gratzel, M.; Mullen, K.; RSC Adv., 2014, 4, 54130.

76. Shen, Z.; Zhang, X.; Giordano, F.; Hu, Y.; Hua, J.; Zakeeruddin, S. M.; Tian, H.; Grätzel, M.; Mater. Chem. Front., 2017, 1, 181.

77. Mehmood, U.; Ahmed, S.; Hussein, I.A.; Harrabi, K.; Electro. Acta, 2015, 173, 607.

78. Baviskar, P.K.; Dubal, D.P.; Majumder, S.; Ennaoui, A.; Sankapal, B.R.; J. of Photochem. \& Photobiol. A: Chem., 2016, 318, 135.

79. Lu, X.; Lan, T.; Qin, Z.; Wang, Z. S.; Zhou, G.; ACS Appl. Mater. \& Inter. 2014, 6, 19308

80. Lee, K. M.; Hsu, Y. C.; Ikegami, M.; Miyasaka, T.; Justin Thomas, K. R.; Lin, J. T.; Ho, K. C.; J. of Power Sources, 2011, 196, 2416.

81. Luo, J.; Wan, Z.; Jia, C.; Wang, Y.; Wu, X.; Electro. Acta, 2016, 215, 506.

82. Saxena, V.; Veerender, P.; Chauhan, A.; Jha, P.; Aswal, D.; Gupta, S.; Appl. Phys. Lett., 2012, 100, 81

83. Saxena, V.; Veerender, P.; Gusain, A.; Jha, P.; Singh, J.; Koiry, S. P.; Varde, P. V.; Chauhan, A. K., Aswal, D. K.; Gupta, S. K.; Org. Electr., 2013, 14, 3098.

84. Wei, L.; Yang, Y.; Fan, R.; Na, Y.; Wang, P.; Dong, Y.; Thin Sol. Films, 2015 $592,14$.

85. Babu, D.D.; Su, R.; Naik, P.; El-Shafei, A.; Adhikari, A.V.; Dyes and Pigm., 2017, 141, 112

86. Naik, P.; Su, R.; El-Shafei, A.; Adhikari, A.V.; Inorg. Chem. Comm., 2017, 86, 241. 